Supporting Information for

\title{
Non-Isocyanate and Catalyst-Free Synthesis of A Recyclable Polythiourethane with Cyclic Structure
}

Shuang Wu,${ }^{\dagger}$ Ming Luo, ${ }^{*}, \dagger$ Donald J. Darensbourg,,$*$, Dandan Zeng, ${ }^{\dagger}$ Yuhua Yao, ${ }^{\dagger}$ Xiaobing Zuo, ${ }^{\dagger}$ Xin $\mathrm{Hu}^{\dagger}$ and Dawei Tan ${ }^{\dagger}$

†School of Materials Engineering, Changshu Institute of Technology, Changshu, Jiangsu 215500, China.

* Department of Chemistry, Texas A\&M University, College Station, Texas 77843, United States.

\author{
*Corresponding Author(s): \\ * tianyaguzhao@zju.edu.cn (M. L); \\ *djdarens@chem.tamu.edu (D.J. D)
}

Number of pages: 32

Number of figures: 50

\section{Table of Contents}

Experimental S3

Figure S1. ${ }^{1} \mathrm{H}$ NMR (DMSO-d6) spectrum of the crude product of entry 1 in Table 1.......... S5

Figure S2. ${ }^{1} \mathrm{H}$ NMR (DMSO-d6) spectrum of the crude product of entry 2 in Table $1 . . . \ldots \ldots \ldots$. S6

Figure S3. ${ }^{1} \mathrm{H}$ NMR (DMSO-d6) spectrum of the crude product of entry 3 in Table 1........... S6

Figure S4. ${ }^{1} \mathrm{H}$ NMR (DMSO-d6) spectrum of the crude product of entry 4 in Table 1.......... S7

Figure S5. ${ }^{1} \mathrm{H}$ NMR (DMSO-d6) spectrum of the crude product of entry 5 in Table $1 . \ldots \ldots \ldots .$. S7

Figure S6. ${ }^{1} \mathrm{H}$ NMR (DMSO-d6) spectrum of the crude product of entry 6 in Table $1 . \ldots \ldots \ldots .$. S 8

Figure S7. ${ }^{1} \mathrm{H}$ NMR (DMSO-d6) spectrum of the crude product of entry 7 in Table 1.......... S8

Figure S8. ${ }^{1} \mathrm{H}$ NMR (DMSO-d6) spectrum of the crude product of entry 8 in Table $1 . \ldots \ldots \ldots .$. S9

Figure S9. ${ }^{1} \mathrm{H}$ NMR (DMSO-d6) spectrum of the crude product of entry 9 in Table 1.......... S9

Figure S10. ${ }^{1} \mathrm{H}$ NMR (DMSO-d6) spectrum of the crude product of entry 10 in Table 1......... S10

Figure S11. ${ }^{1} \mathrm{H}$ NMR (DMSO-d6) spectrum of the crude product of entry 11 in Table $1 . \ldots . . . .$. S10

Figure S12. ${ }^{1} \mathrm{H}$ NMR (DMSO-d6) spectrum of the crude product of entry 12 in Table $1 . \ldots \ldots .$. S11

Figure S13. ${ }^{1} \mathrm{H}$ NMR (DMSO-d6) spectrum of the crude product of entry 13 in Table 1........ S11

Figure S14. ${ }^{1} \mathrm{H}$ NMR (DMSO-d6) spectrum of the crude product of entry 14 in Table 1........ S12

Figure S15. ${ }^{1} \mathrm{H}$ NMR (DMSO-d6) spectrum of the crude product of entry 15 in Table $1 . \ldots \ldots . . . \mathrm{S} 12$

Figure S17. ${ }^{1} \mathrm{H}$ NMR (DMSO-d6) spectrum of the crude product of entry 17 in Table 1......... S13

Figure S18. Comparison of ${ }^{1} \mathrm{H}$ NMR (DMSO-d6) spectra of thermal degradation product of the COS-MeAz copolymer of different heating time. $\mathrm{S} 14$

Figure S19. ${ }^{1} \mathrm{H} \mathrm{NMR}\left(\mathrm{CDCl}_{3}\right)$ spectrum of the distilled product from the thermal 
decomposition product of the lead absorption.

Figure S20. Video screenshots of the atmospheric copolymerization progress. ............... S15

Figure S21. Original full-range MALDI-TOF-MS spectrum of entry 2 in Table 1.......... S17

Figure S22. Original full-range MALDI-TOF-MS spectrum of entry 5 in Table 2........... S17

Figure S23. The DSC curve with the complete three run of the copolymer of

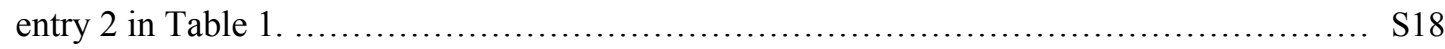

Figure S24. The powder X-ray diffraction (XRD) curve of the copolymer. ................ S18

Figure S25. The LC-MS spectrum of the cyclic product. ............................... S19

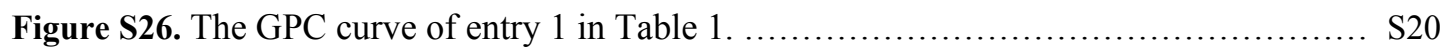

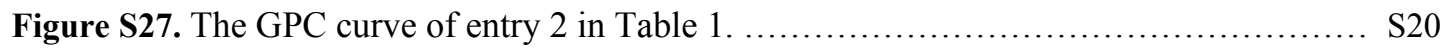

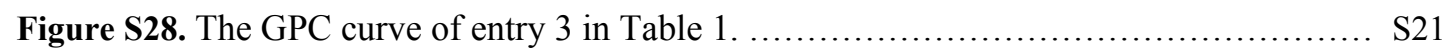

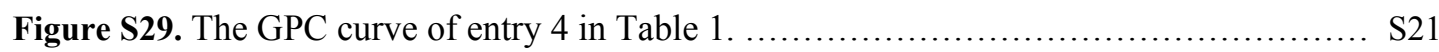

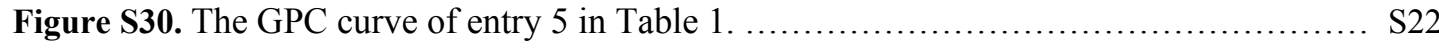

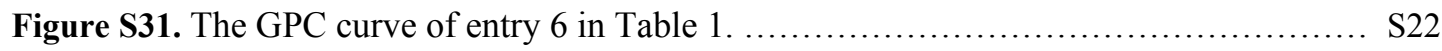

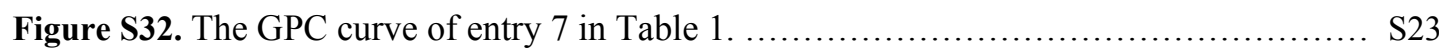

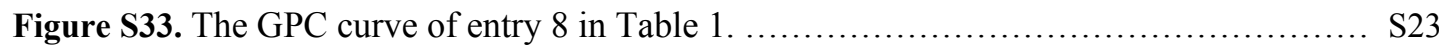

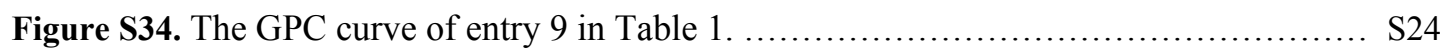

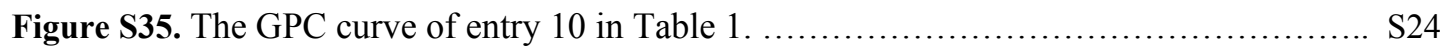

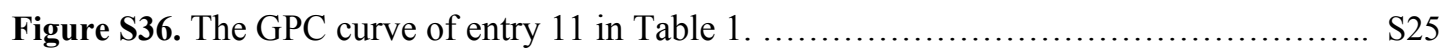

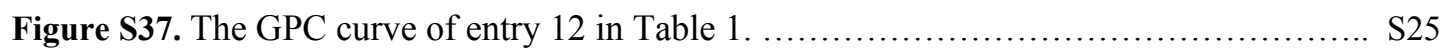

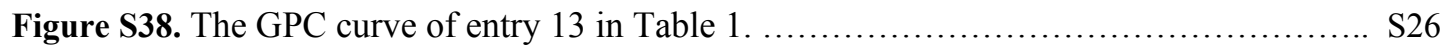

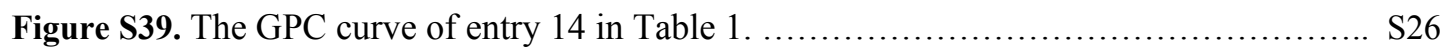

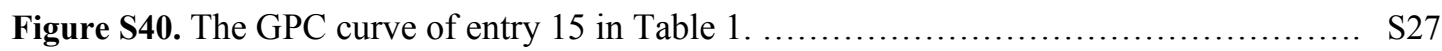

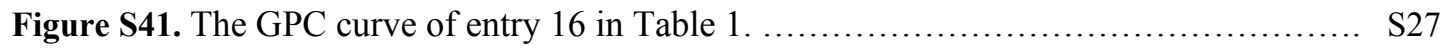

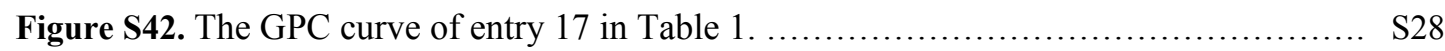

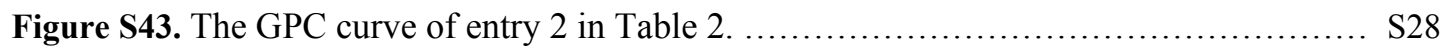

Figure S44. The GPC curve of entry 3 in Table 2 .................................... S29

Figure S45. The GPC curve of entry 4 in Table 2. .................................... S29

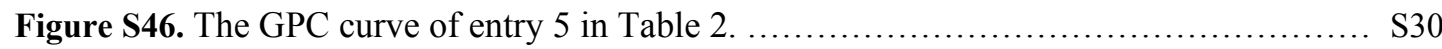

Figure S47. The GPC curve of entry 6 in Table 2. .................................... S30

Figure S48. The XPS spectrum of the black solid in lead recovery. ..................... S31

Figure S49. XPS spectra of the $\mathrm{Pb} 4 \mathrm{f}$ and depicted elemental quantification. ............... S31

Figure S50. XPS spectra of the $\mathrm{Cl} 2 \mathrm{p}$ and depicted elemental quantification. ............... S32

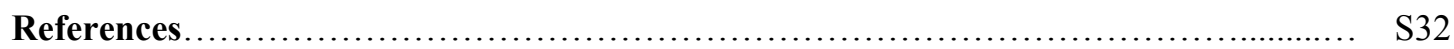




\section{EXPERIMENTAL}

Materials. Carbonyl sulfide (COS) (99.9\%) was purchased from the APK (Shanghai) Gas Company LTD and used directly. 2-methyl aziridine (MeAz) was synthesized according to literature ${ }^{1}$. Anhydrous solvents and all the other reagents were purchased from Energy Chemical and used without further purification.

\section{Characterizations.}

Nuclear Magnetic Resonance (NMR). ${ }^{1} \mathrm{H}$ and ${ }^{13} \mathrm{C}$ NMR spectra were measured on a Bruker Avance $500 \mathrm{MHz}$ NMR spectrometer using deuterated dimethyl sulfoxide as solvent and tetramethylsilane (TMS, $\delta=0$ ) as internal reference.

Gel Permeation Chromatography (GPC). The number- $\left(M_{\mathrm{n}}\right)$ and weight- $\left(M_{\mathrm{w}}\right)$ average molecular weights and dispersity $\left(\nexists=M_{\mathrm{w}} / M_{\mathrm{n}}\right)$ of the polymers were estimated by a Waters 1515 gel permeation chromatography system. $\mathrm{DMF} / \mathrm{LiBr}$ solution $(0.05 \mathrm{M} \mathrm{LiBr})$ was used as eluent at a flow rate of $1 \mathrm{~mL} / \mathrm{min}$.

Thermogravimetry (TG). Thermogravimetric analysis was carried out on a Netzsch TG 209 F3 and the sample was heated from room temperature to $800^{\circ} \mathrm{C}$ at a rate of $10^{\circ} \mathrm{C} / \mathrm{min}$ under nitrogen atmosphere.

Differential Scanning Calorimetry (DSC). The glass transition temperature $\left(T_{\mathrm{g}}\right)$ of the resultant polymers were determined by using a Mettler Toledo differential scanning calorimetry. The sample was heated from room temperature to $195{ }^{\circ} \mathrm{C}$ at a rate of $10{ }^{\circ} \mathrm{C} / \mathrm{min}$ and kept isothermal for $3 \mathrm{~min}$, then cooled to $-80^{\circ} \mathrm{C}$ at a rate of $-10{ }^{\circ} \mathrm{C} / \mathrm{min}$ and kept isothermal for $3 \mathrm{~min}$, finally heated from -80 ${ }^{\circ} \mathrm{C}$ to $195^{\circ} \mathrm{C}$ at a rate of $10{ }^{\circ} \mathrm{C} / \mathrm{min} . T_{\mathrm{g}}$ was determined from the third run.

Matrix-Assisted Laser Desorption/Ionization Time of Flight Mass Spectrometry (MALDITOF-MS). MALDI-TOF spectra were obtained on a Bruker Microflex (nitrogen laser of $337 \mathrm{~nm}$ ) operating in linear mode. The polymer sample (entry 2, Table 1) solutions (10 $\mathrm{mg} / \mathrm{mL}$ DMF) and a DCTB solution (matrix, $10 \mathrm{mg} / \mathrm{mL}$ THF) were mixed in a 10:1 volume ratio, $1 \mu \mathrm{L}$ of which was then spotted onto the MALDI-TOF sample plate before being air-dried. 
Inductively coupled plasma atomic emission spectroscopy (ICP-AES). The concentration of metal ion was determined on a ICP-AES PE Optimia8000.

Liquid Chromatography-Mass Spectrum (LC-MS). The Mass spectrum of the cyclic product was obtained on a Agilent 1260/6120 liquid chromatography-sass instrument. Methanol was used as solvent.

Polymerization. A typical synthetic procedure for the preparation of COS-MeAz copolymer is given below as an example (entry 2 in Table 1$)$. MeAz $(0.3 \mathrm{~mL}, 4.20 \mathrm{mmol})$ and THF (1 mL) were sealed in Schlenk tubes and used through a Schlenk Line under $\mathrm{N}_{2}$. They were added into a $10 \mathrm{ml}$ autoclave equipped with a magnetic stirrer under air atmosphere, after seal of the autoclave, $2 \mathrm{MPa}$ COS was added, then the reaction mixture was stirred at $20^{\circ} \mathrm{C}$ for 2 hours. The autoclave was cooled with ice water after the reaction, then the COS was released slowly. A portion of the crude product was sent for NMR measurement to determine the selectivity of the copolymer. The remaining crude product was precipitated in methanol three times $(3 \times 50 \mathrm{~mL})$, and the precipitate was dried in a vacuum oven at $60{ }^{\circ} \mathrm{C}$ for $12 \mathrm{~h}$ to obtain pure product.

\section{Characterization data of monomer, copolymer and cyclic product.}

Characterization data for 2-methyl aziridine (MeAz) monomer. ${ }^{1} \mathrm{H}$ NMR (500 MHz, DMSO-d6), $\delta$ (TMS, ppm): $1.78(\mathrm{~s}, 1 \mathrm{H}, \mathrm{CH}), 1.51\left(\mathrm{~s}, 1 \mathrm{H}, \mathrm{CH}_{2}\right), 1.04\left(\mathrm{~d}, 1 \mathrm{H}, \mathrm{CH}_{2} ; 3 \mathrm{H}, \mathrm{CH}_{3}\right), 0.86(\mathrm{~s}, 1 \mathrm{H}, \mathrm{NH})$. There are overlaps between the three peaks of one proton of methene group, three protons of methyl group and one proton of NH group. The result is corresponding with literature. ${ }^{2}$

Characterization data for COS-MeAz copolymer. As for entry 2 in Table 1, a white solid was obtained in $95 \%$ yield. $M_{\mathrm{w}}=15.2 \mathrm{~kg} / \mathrm{mol}, M_{\mathrm{w}} / M_{\mathrm{n}}=1.68 .{ }^{1} \mathrm{H}$ NMR (500 MHz, DMSO-d6), $\delta$ (TMS, ppm): $8.15(\mathrm{~s}, 1 \mathrm{H}, \mathrm{NH}), 3.81(\mathrm{~m}, 1 \mathrm{H}, \mathrm{CH}), 2.87\left(\mathrm{~m}, 2 \mathrm{H}, \mathrm{CH}_{2}\right), 1.09$ (d, 3H, $\left.\mathrm{CH}_{3}\right) .{ }^{13} \mathrm{C}$ NMR $(125$ $\left.\mathrm{MHz}, \mathrm{CDCl}_{3}\right), \delta(\mathrm{TMS}, \mathrm{ppm}): 164.69(\mathrm{C}=\mathrm{O}), 47.71,34.32,19.54$.

Characterization data for Cyclic Product. A clear light yellow liquid. ${ }^{1} \mathrm{H}$ NMR $(500 \mathrm{MHz}$, DMSOd6), $\delta(\mathrm{TMS}, \mathrm{ppm}): 8.07(\mathrm{~s}, 1 \mathrm{H}, \mathrm{NH}), 3.86(\mathrm{~m}, 1 \mathrm{H}, \mathrm{CH}), 3.46\left(\mathrm{~m}, 1 \mathrm{H}, \mathrm{CH}_{2}\right), 2.98\left(\mathrm{~m}, 1 \mathrm{H}, \mathrm{CH}_{2}\right)$, $1.19\left(\mathrm{~d}, 3 \mathrm{H}, \mathrm{CH}_{3}\right) .{ }^{13} \mathrm{C} \mathrm{NMR}\left(125 \mathrm{MHz}, \mathrm{CDCl}_{3}\right), \delta(\mathrm{TMS}, \mathrm{ppm}): 175.66(\mathrm{C}=\mathrm{O}), 51.40,36.77,20.74$. 


\section{${ }^{1} \mathrm{H}$ and ${ }^{13} \mathrm{C}$ NMR spectra}

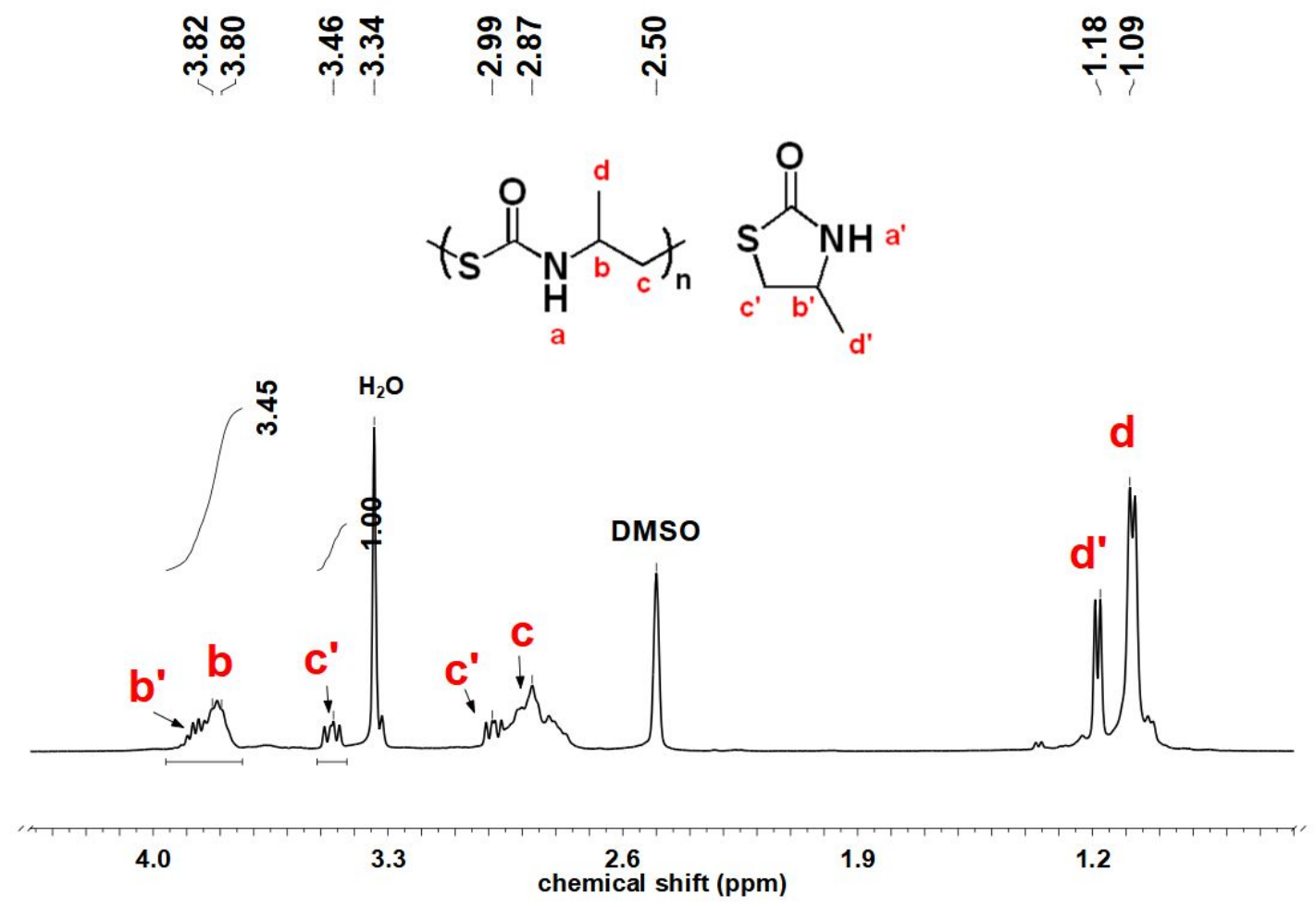

Figure S1. ${ }^{1} \mathrm{H}$ NMR (DMSO-d6) spectrum of the crude product of entry 1 in Table 1.

The resonance of methine proton in copolymer and the cyclic product appeared at $3.80 \mathrm{ppm}$ and $3.82 \mathrm{ppm}$, respectively, and they were assigned to peak $\mathbf{b}$ and $\mathbf{b}$ ' which have an overlap with each other. The resonance of the two methylene protons of the cyclic product were found at 3.46 ppm and $2.99 \mathrm{ppm}$, and they were assigned to peaks $\mathbf{c}^{\prime}$. As the peak $\mathbf{c}^{\prime}$ at $3.46 \mathrm{ppm}$ was isolated and could be well-defined integrated (set Area to 1), we assumed that the integral of peak $\mathbf{b}^{\prime}$ and peak c' $(3.46 \mathrm{ppm})$ were the same, then the integral Area of $\mathbf{b}^{\prime}$ 'is 1 . The integral of peak $\mathbf{b}$ could be achieved by the Subtract 1 with the total integral of $\mathbf{b}$ and $\mathbf{b}^{\prime}$ (Area $=3.45$ in Figure S1). Copolymer selectivity $(\%)=\left(\mathrm{A}_{3.28-3.80}-\mathrm{A}_{3.46}\right) / \mathrm{A}_{3.28-3.80}=71 \%$. 


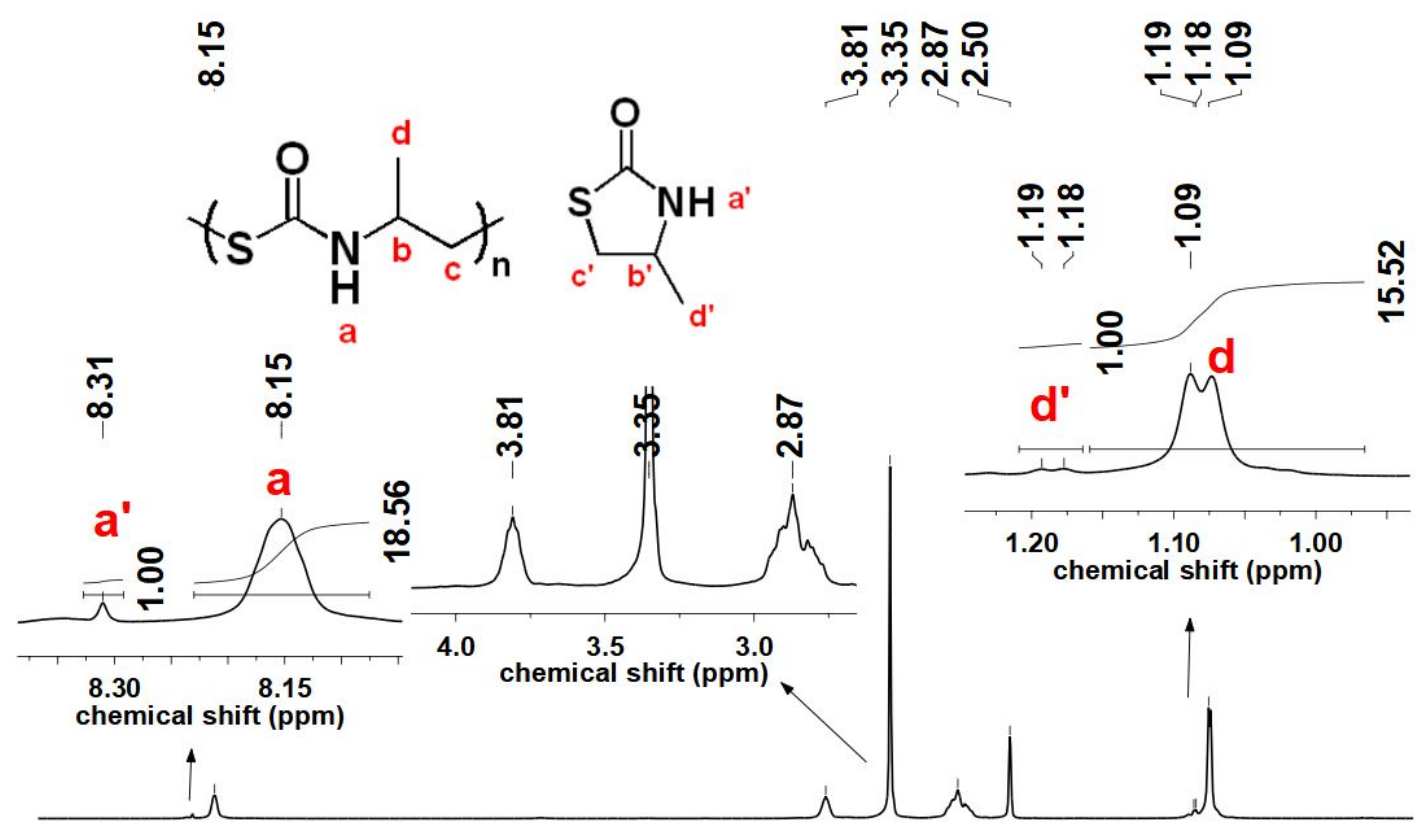

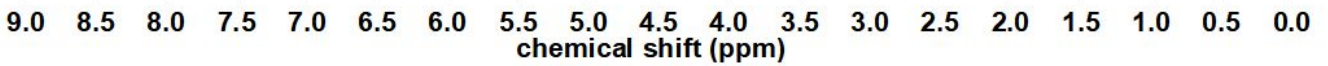

Figure S2. ${ }^{1} \mathrm{H}$ NMR (DMSO-d6) spectrum of the crude product of entry 2 in Table 1.

$\underset{\oplus \infty}{\infty}$

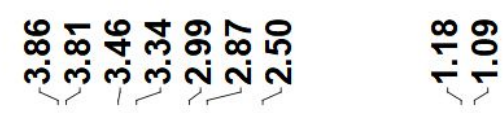<smiles>CC(C)CC(Cl)NC(=O)SC1CCCC1</smiles>

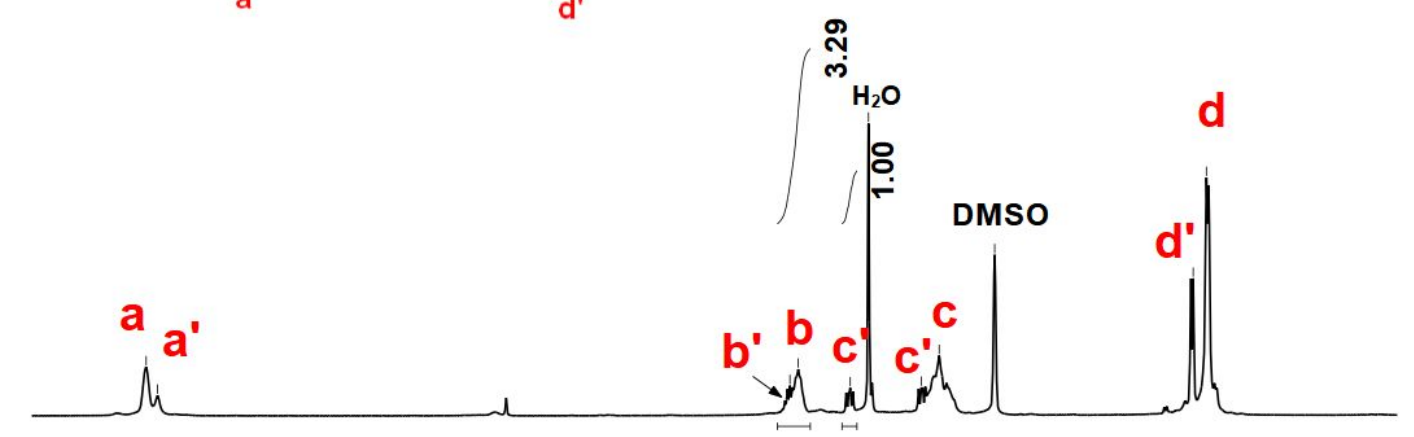

$\begin{array}{llllllllllllllll}8.5 & 8.0 & 7.5 & 7.0 & 6.5 & 6.0 & 5.5 & \begin{array}{c}5.0 \\ \text { chemical shift (ppm) }\end{array} & \begin{array}{l}4.5 \\ \text { shem }\end{array} & 3.0 & 2.5 & 2.0 & 1.5 & 1.0 & 0.5 & 0.0\end{array}$

Figure S3. ${ }^{1} \mathrm{H}$ NMR (DMSO-d6) spectrum of the crude product of entry 3 in Table 1. 

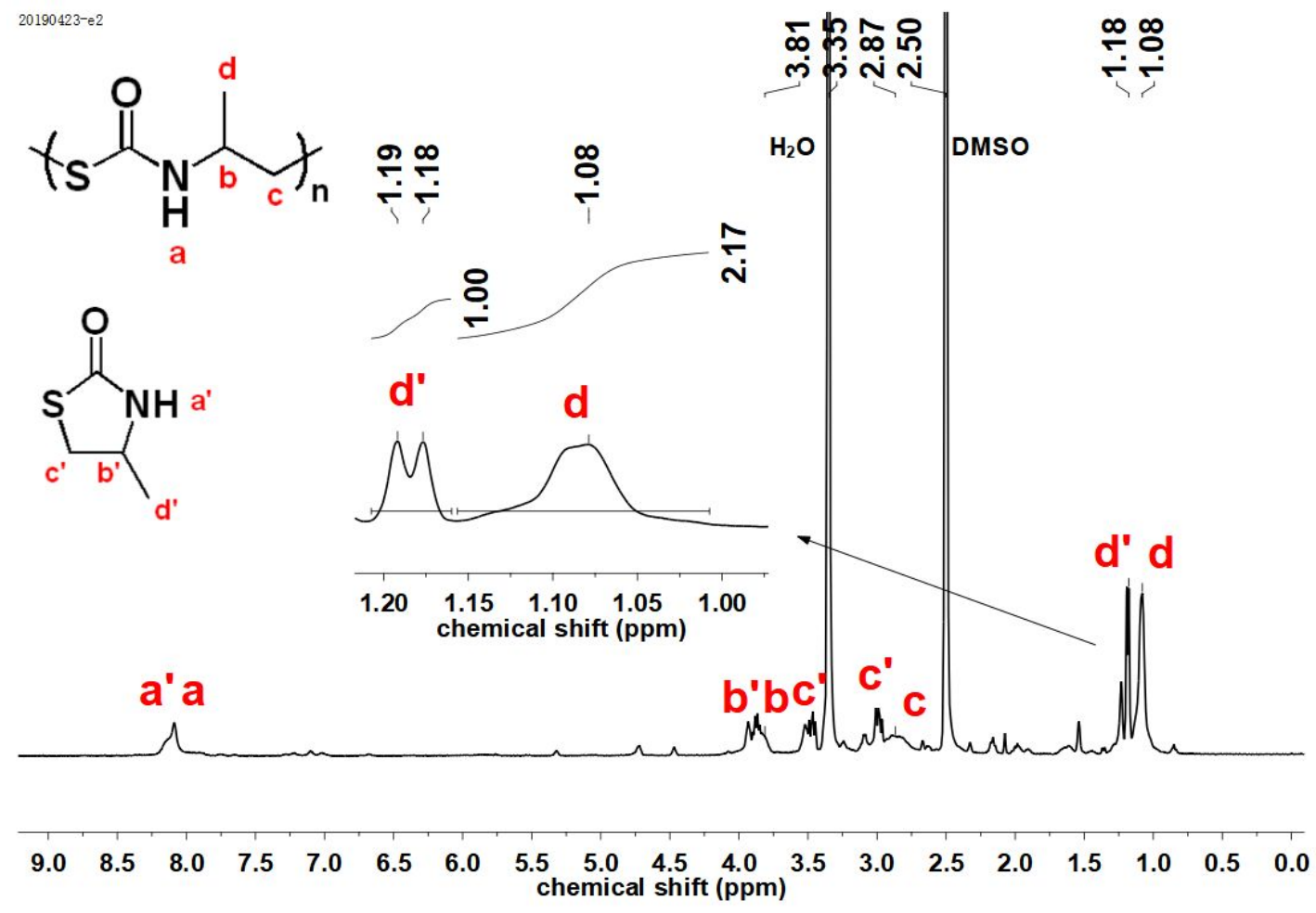

Figure S4. ${ }^{1} \mathrm{H}$ NMR (DMSO-d6) spectrum of the crude product of entry 4 in Table 1.

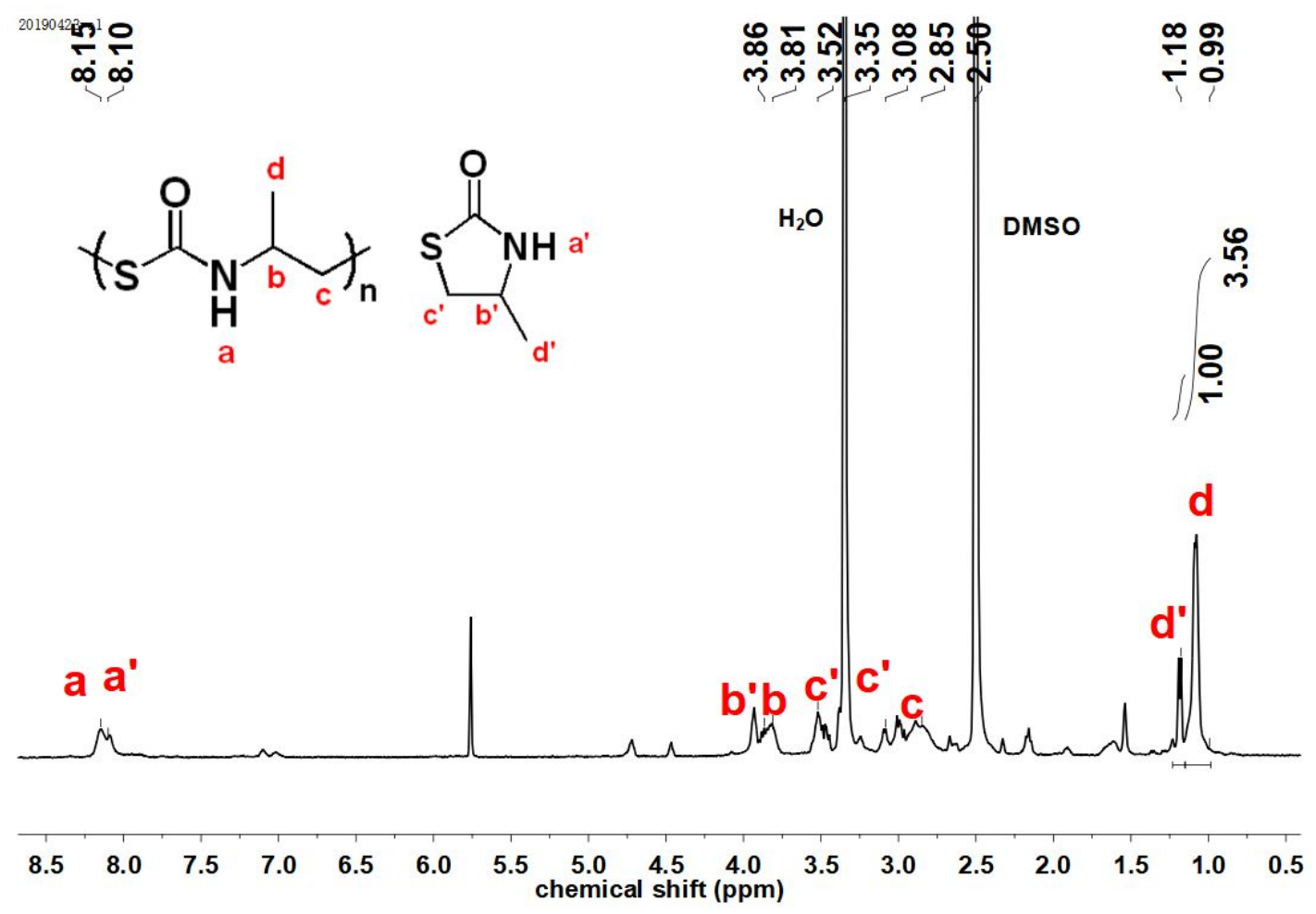

Figure S5. ${ }^{1} \mathrm{H}$ NMR (DMSO-d6) spectrum of the crude product of entry 5 in Table 1. 


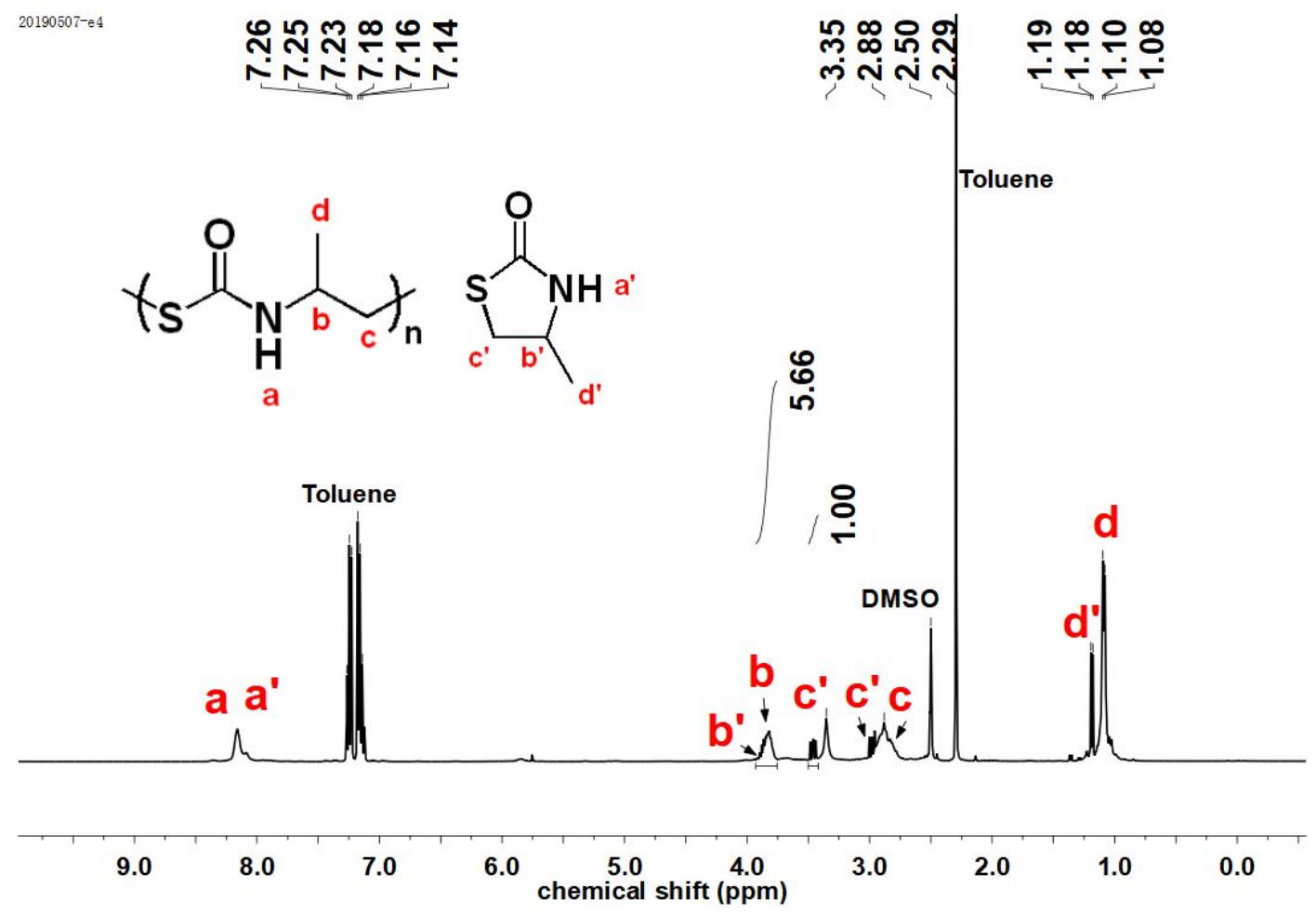

Figure S6. ${ }^{1} \mathrm{H}$ NMR (DMSO-d6) spectrum of the crude product of entry 6 in Table 1.

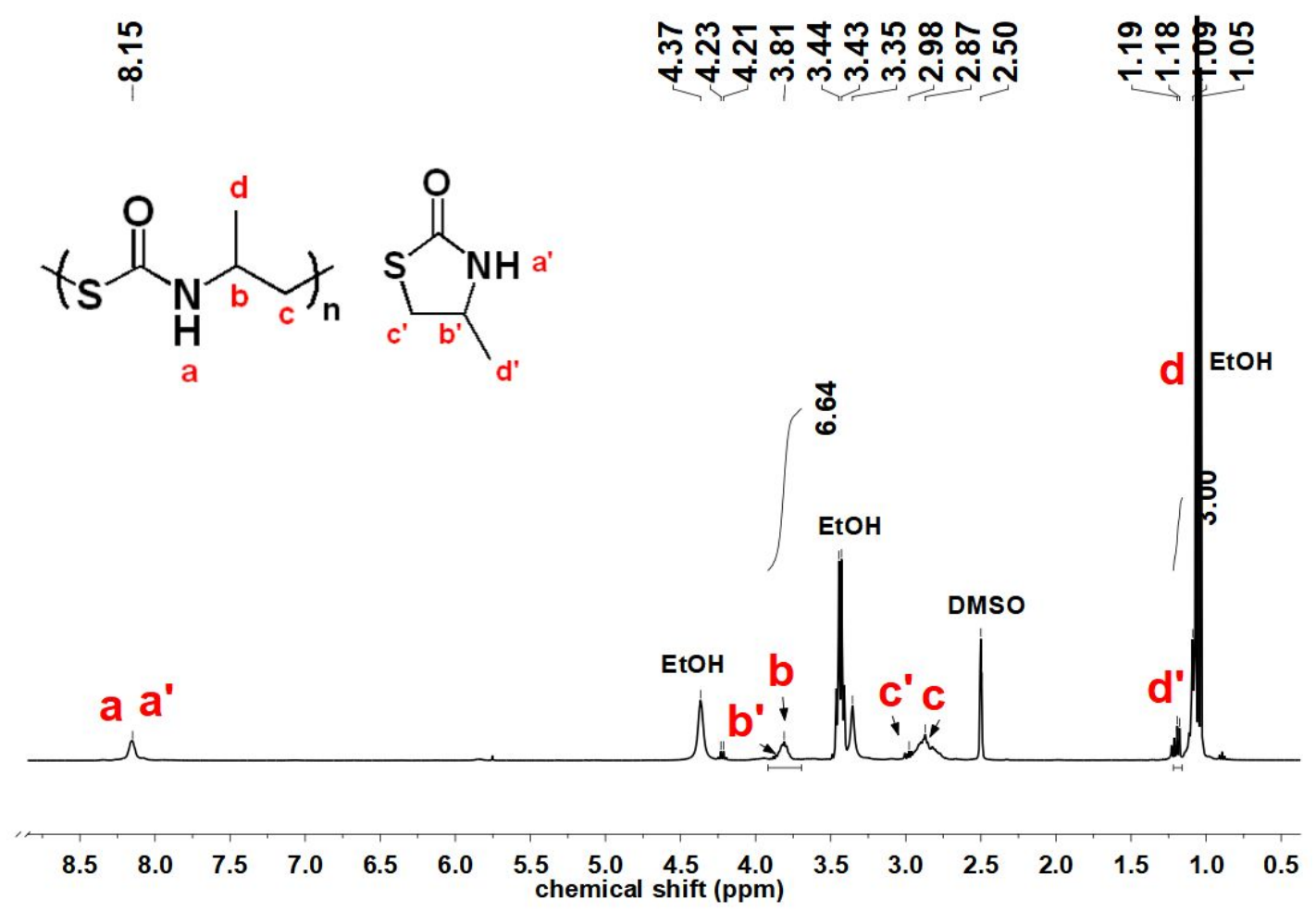

Figure S7. ${ }^{1} \mathrm{H}$ NMR (DMSO-d6) spectrum of the crude product of entry 7 in Table 1. 


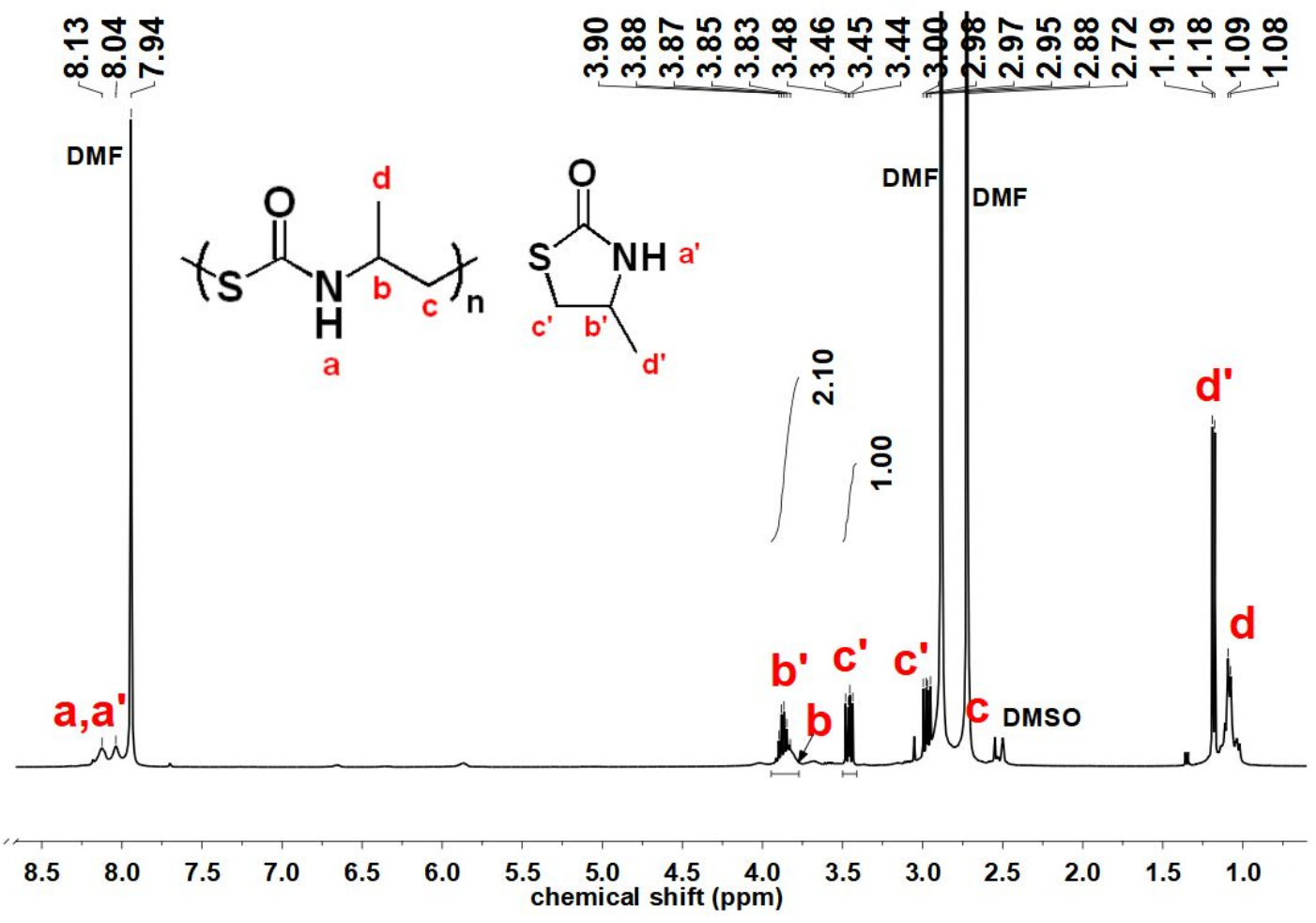

Figure S8. ${ }^{1} \mathrm{H}$ NMR (DMSO-d6) spectrum of the crude product of entry 8 in Table 1.

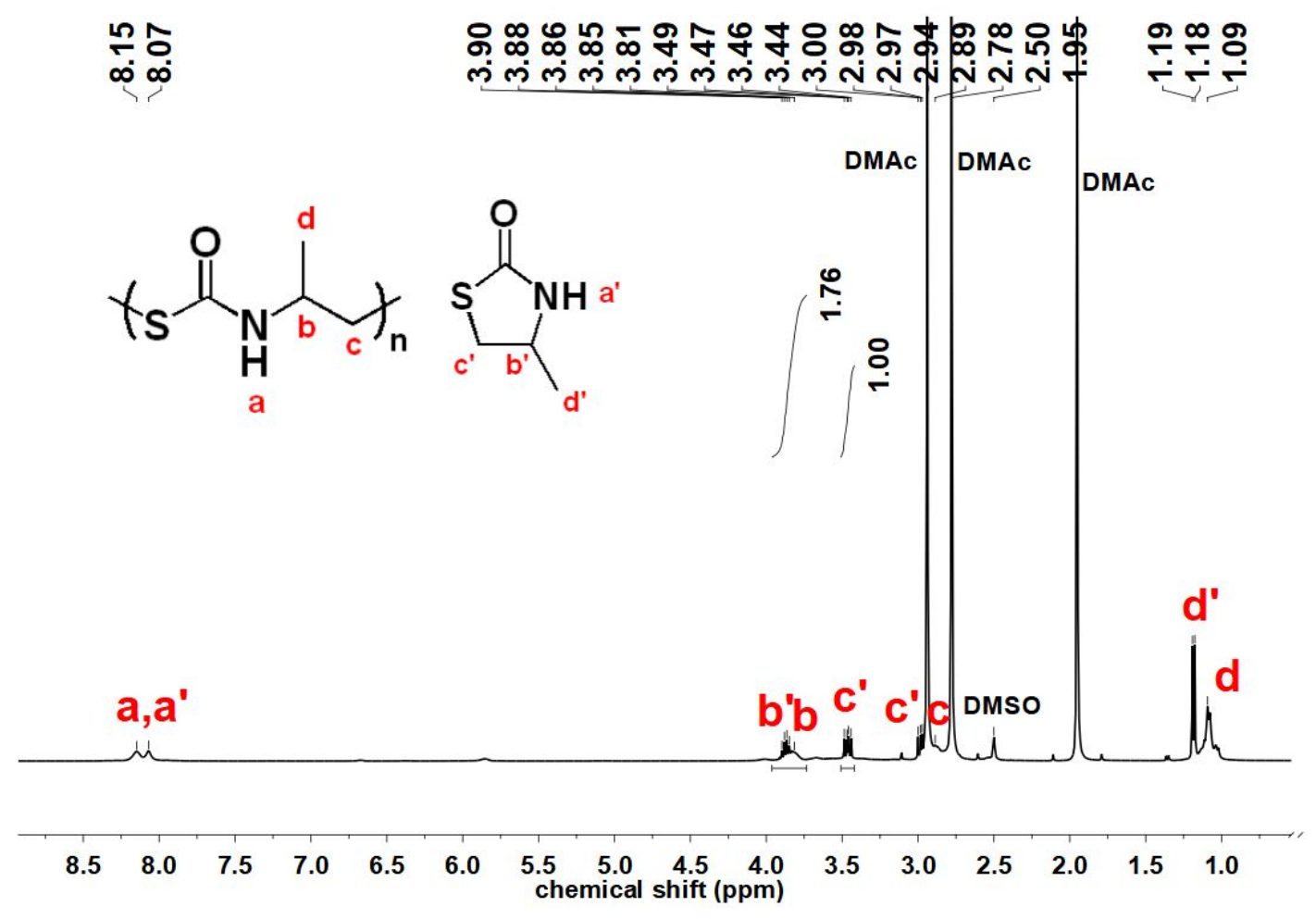

Figure S9. ${ }^{1} \mathrm{H}$ NMR (DMSO-d6) spectrum of the crude product of entry 9 in Table 1. 


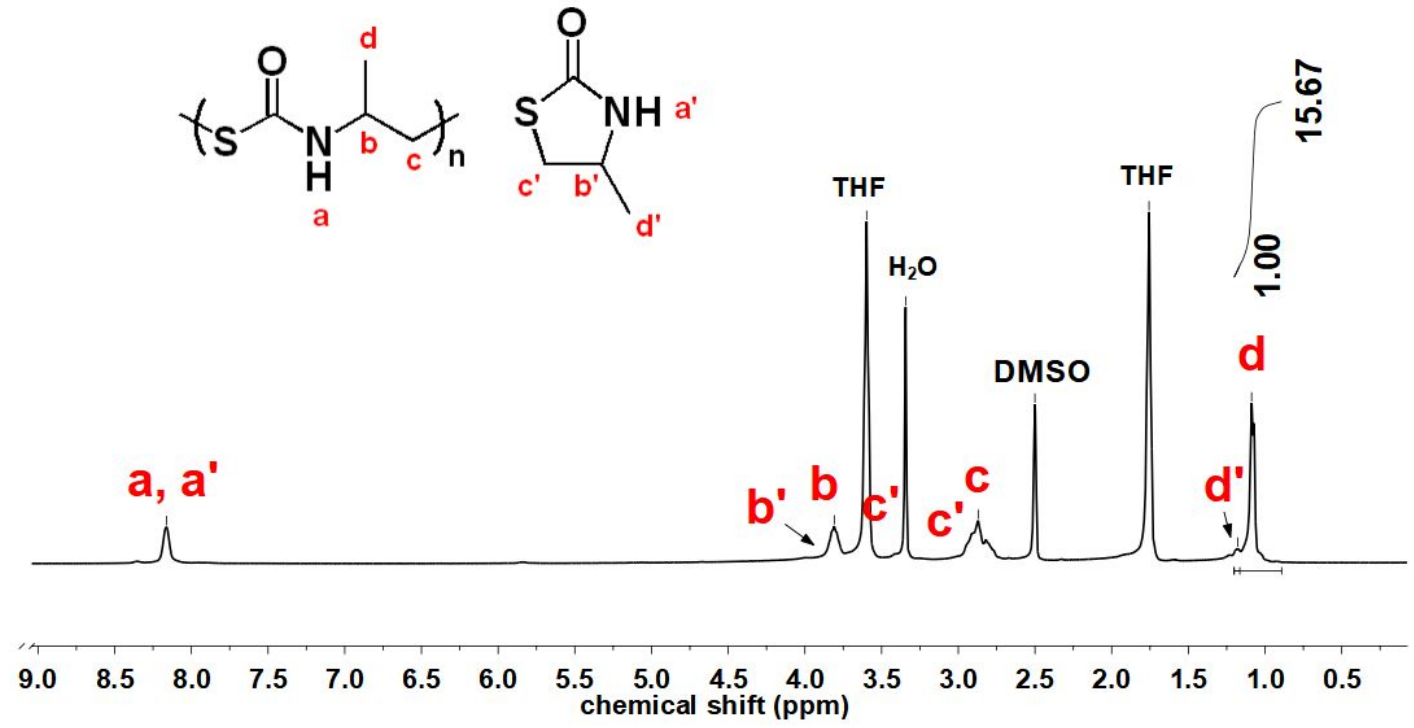

Figure S10. ${ }^{1} \mathrm{H}$ NMR (DMSO-d6) spectrum of the crude product of entry 10 in Table 1.

$\stackrel{\infty}{\infty}$

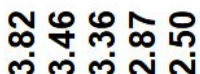

$\stackrel{0}{\check{r}}$<smiles>CCCCSC(=O)NC(Cl)CC(C)(C)C</smiles>

a<smiles>O=C1C[C@@H](Cl)[C@@H](Cl)N1</smiles>

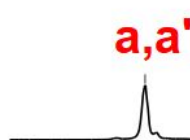

$\mathbf{a}, \mathbf{a}^{\prime}$
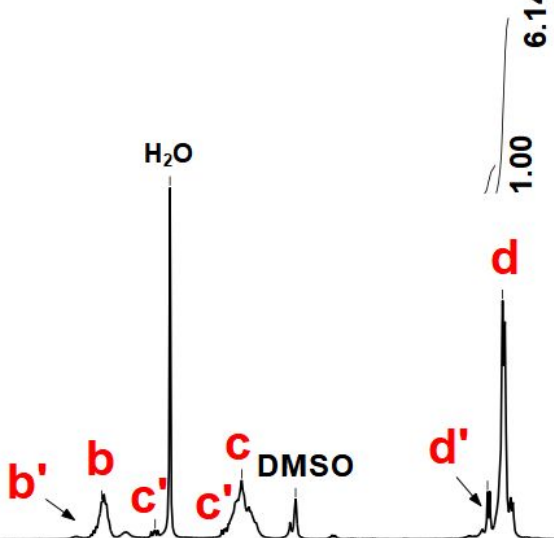

$\stackrel{8}{+}$

d

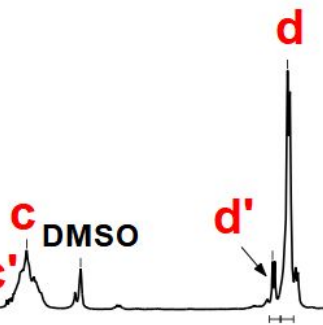

Figure S11. ${ }^{1} \mathrm{H}$ NMR (DMSO-d6) spectrum of the crude product of entry 11 in Table 1. 

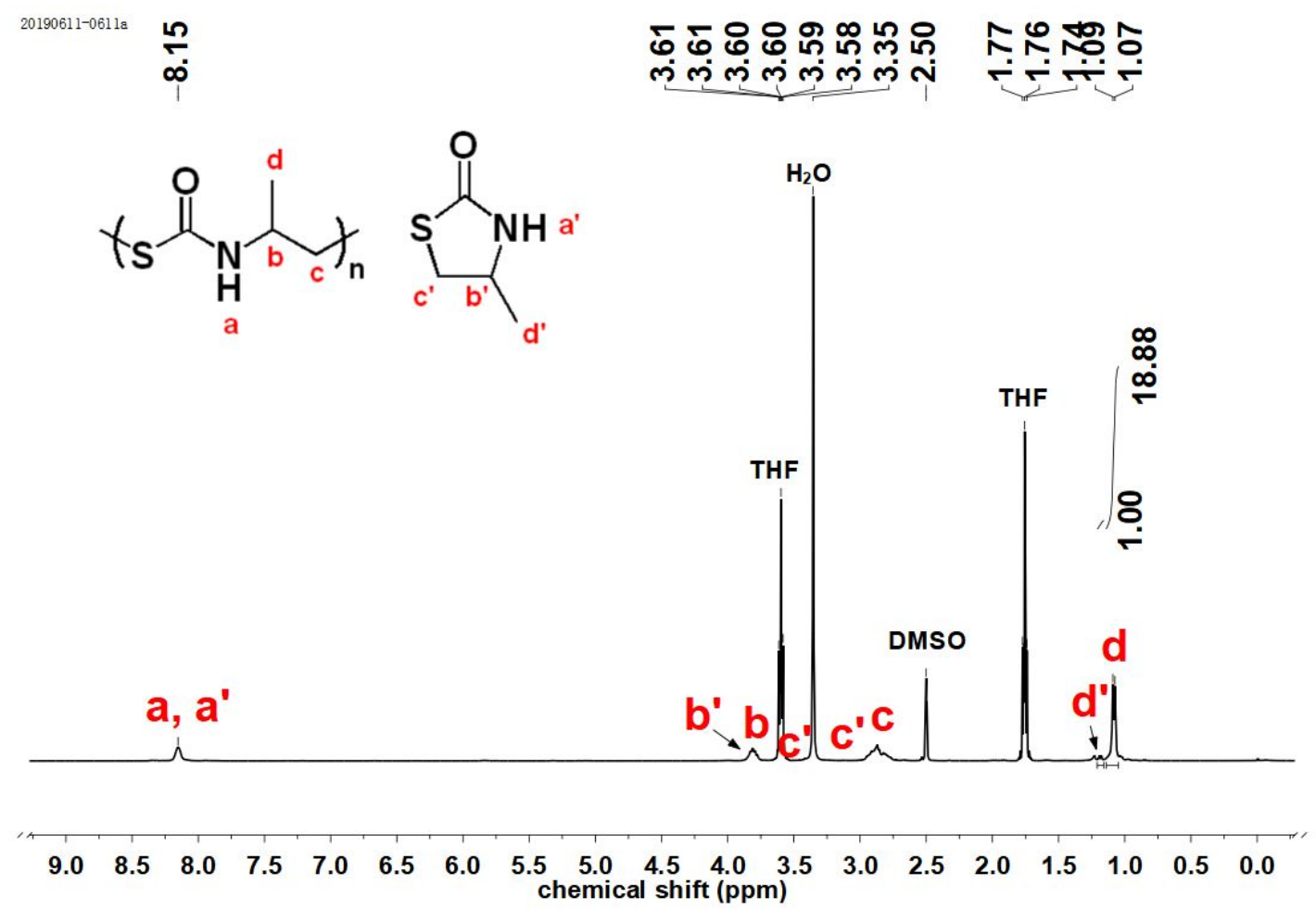

Figure S12. ${ }^{1} \mathrm{H}$ NMR (DMSO-d6) spectrum of the crude product of entry 12 in Table 1.
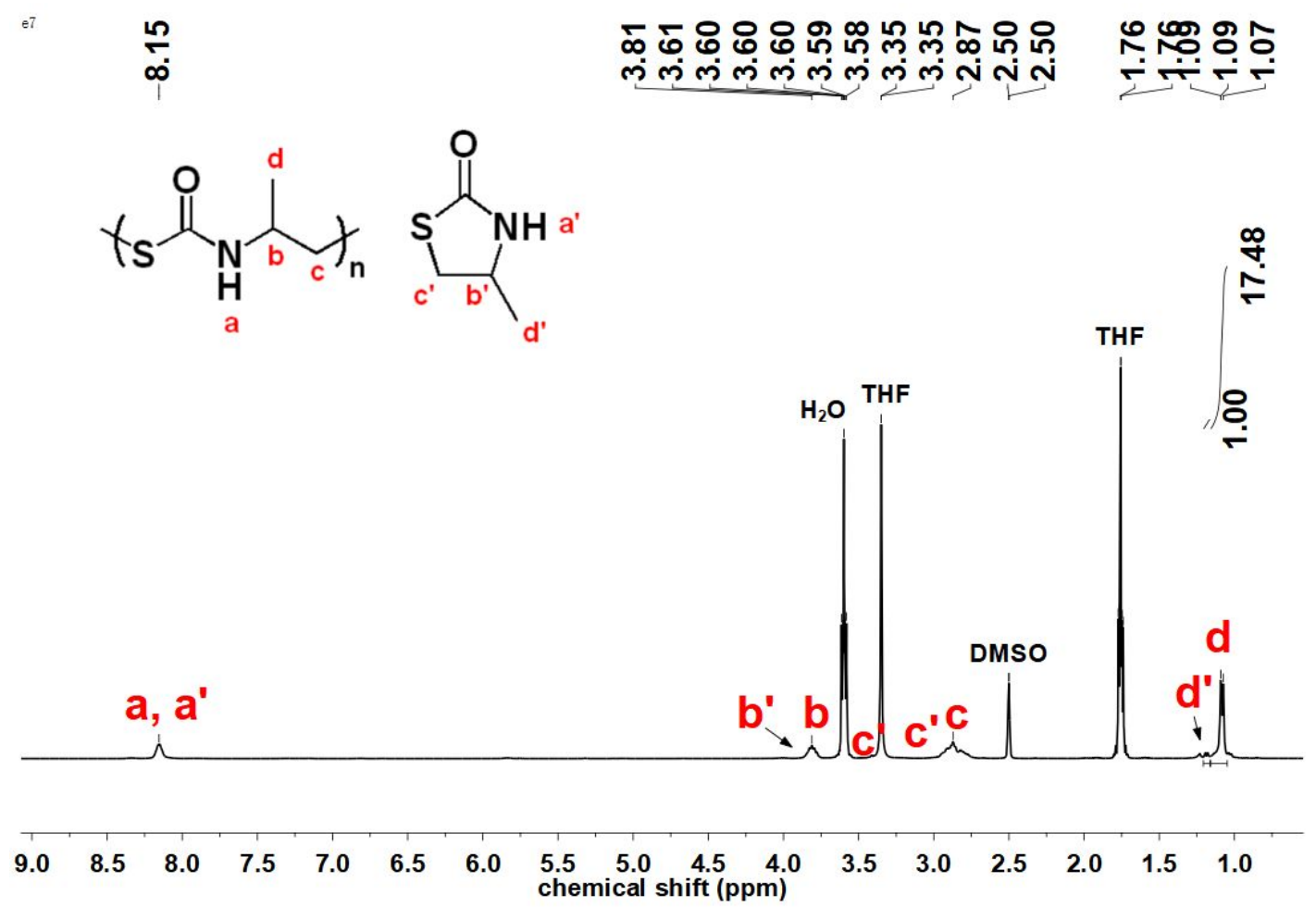

Figure S13. ${ }^{1} \mathrm{H}$ NMR (DMSO-d6) spectrum of the crude product of entry 13 in Table 1. 


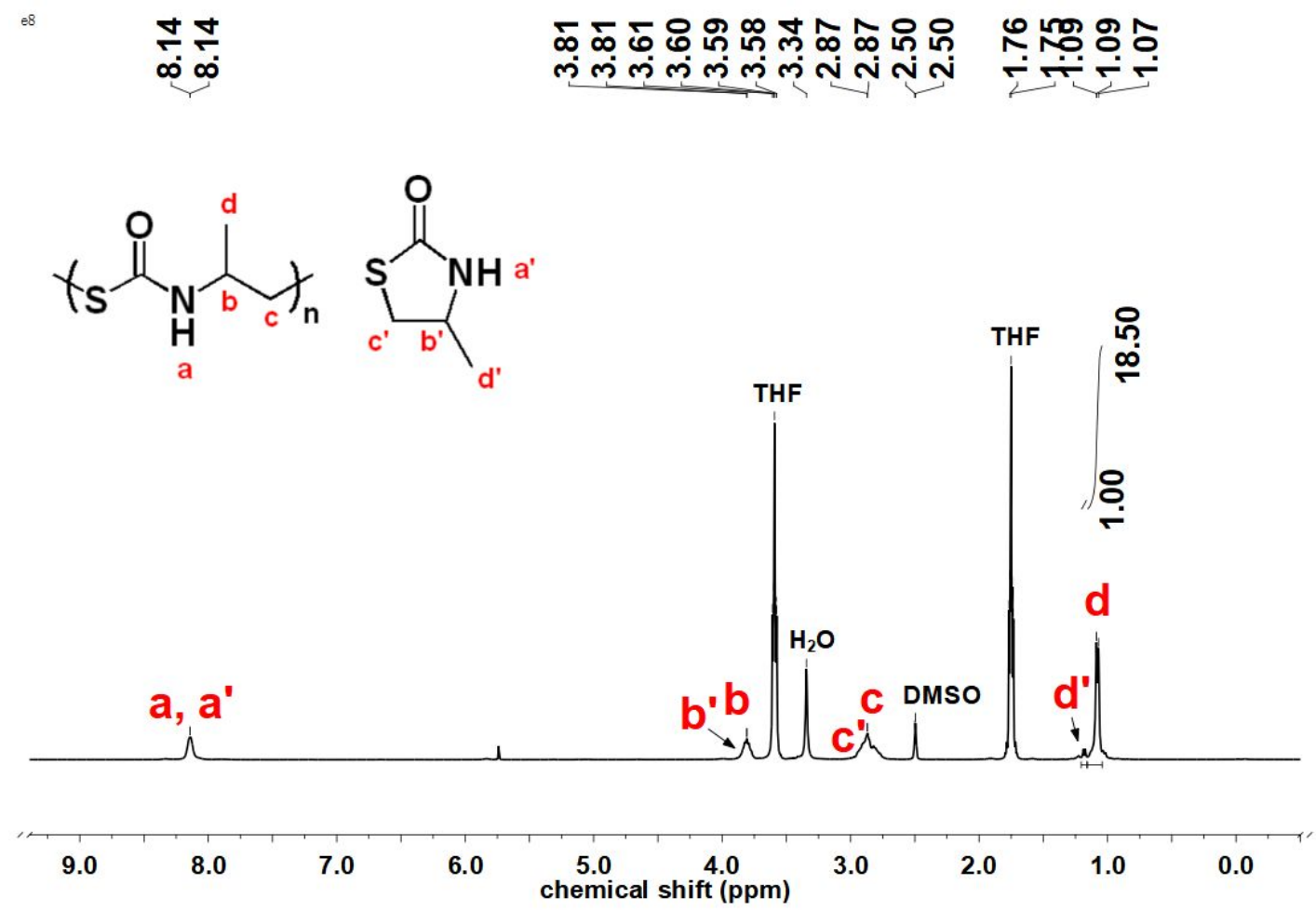

Figure S14. ${ }^{1} \mathrm{H}$ NMR (DMSO-d6) spectrum of the crude product of entry 14 in Table 1.
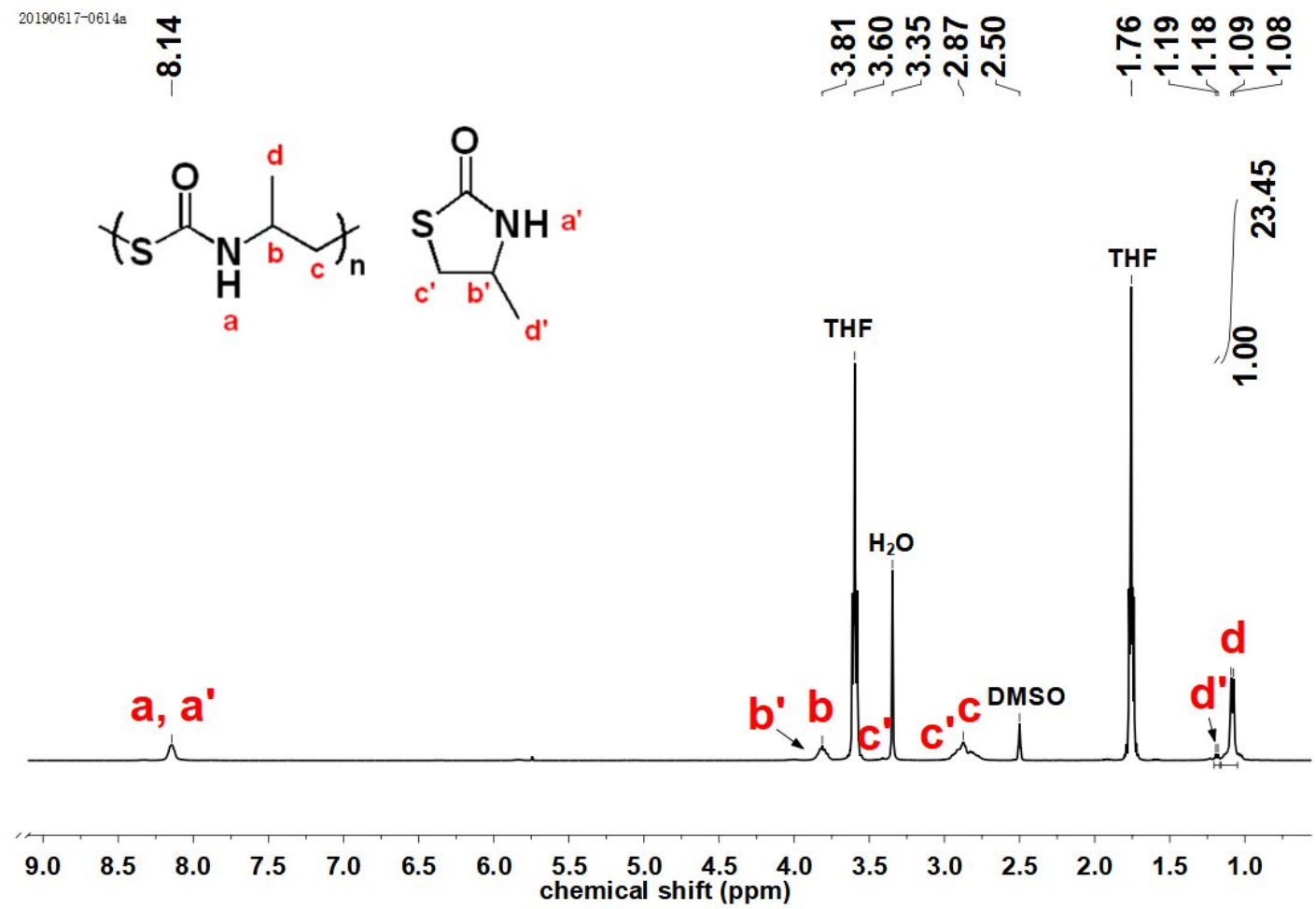

Figure S15. ${ }^{1} \mathrm{H}$ NMR (DMSO-d6) spectrum of the crude product of entry 15 in Table 1. 


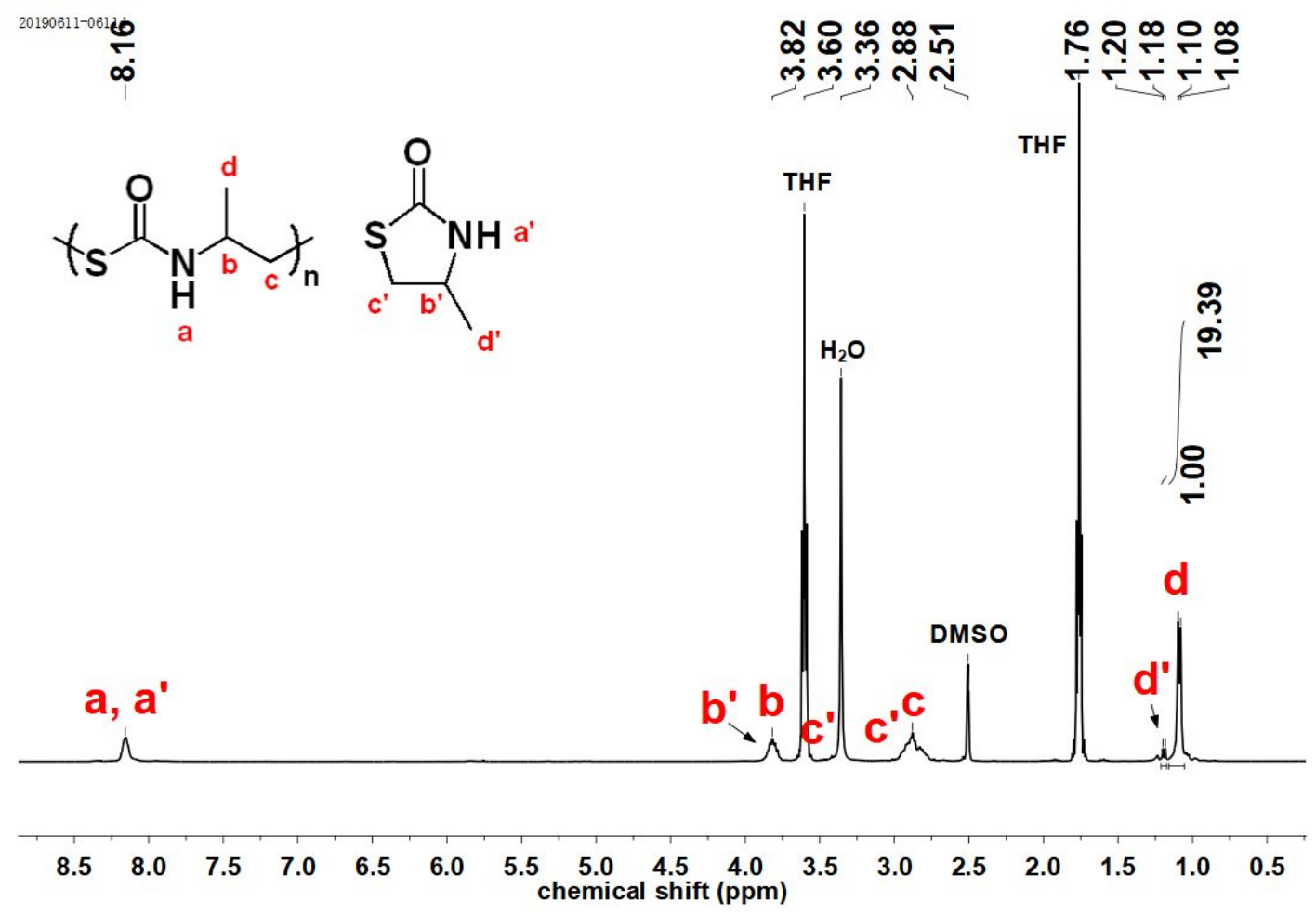

Figure S16. ${ }^{1} \mathrm{H}$ NMR (DMSO-d6) spectrum of the crude product of entry 16 in Table 1.

$\frac{n}{\infty}$

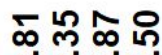

๓่

产送<smiles>CCCSC(=O)N[C@@H](Cl)CC(C)(C)C</smiles>

a<smiles>O=C1C[C@H](Cl)[C@@H](Cl)N1</smiles>

a, a ᄉ

$\begin{array}{llll}8.5 & 8.0 & 7.5 & 7.0\end{array}$

Figure S17. ${ }^{1} \mathrm{H}$ NMR (DMSO-d6) spectrum of the crude product of entry 17 in Table 1. 


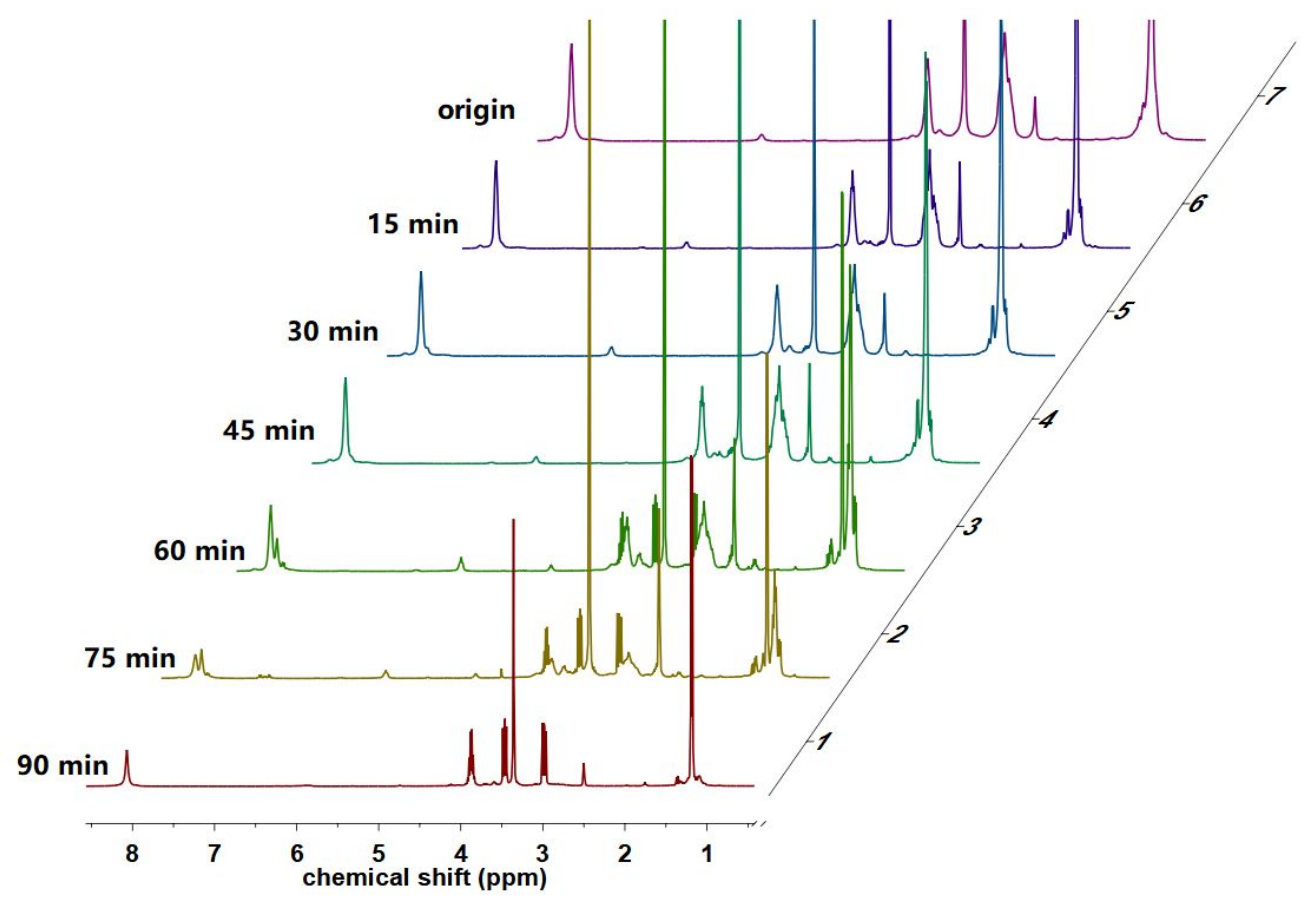

Figure S18. Comparison of ${ }^{1} \mathrm{H}$ NMR (DMSO-d6) spectra (in full region) of thermal degradation product of the COS-MeAz copolymer of different heating time.
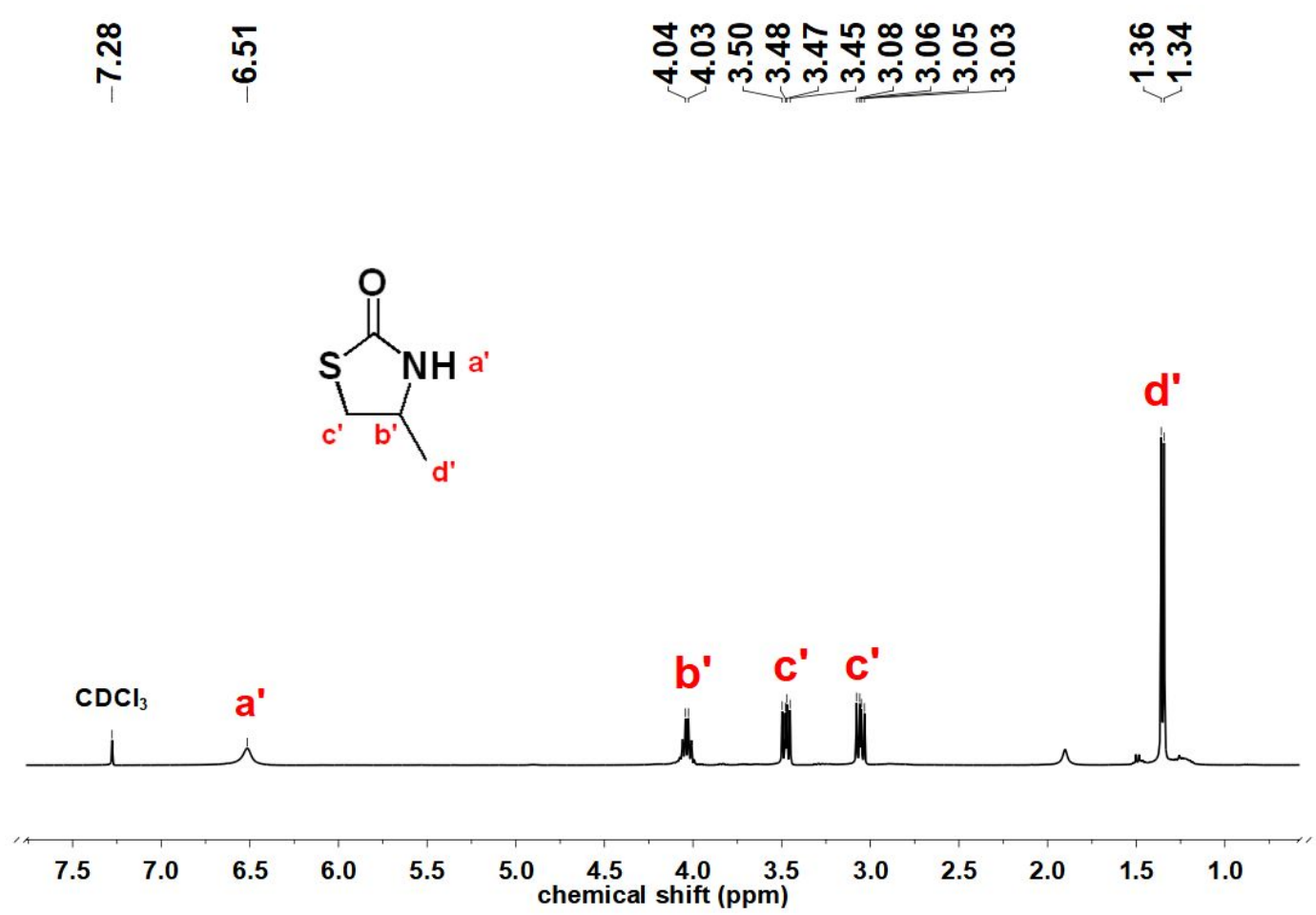

Figure S19. ${ }^{1} \mathrm{H}$ NMR $\left(\mathrm{CDCl}_{3}\right)$ spectrum of the distilled product from the thermal decomposition product of the lead absorption. 


\section{Video screenshots of the atmospheric copolymerization progress.}

The reaction was carried out in a round bottom flask and COS was bubbled into the flask from an air bag through a long needle to the bottom. The flask was sealed with a rubber plug. We recorded video of the five-minutes polymerization progress, and we took the screenshots at 1 second, $0.5 \mathrm{~min}, 1 \mathrm{~min}, 1.5 \mathrm{~min}, 2 \mathrm{~min}, 2.5 \mathrm{~min}, 3 \mathrm{~min}, 3.5$ $\min , 4 \mathrm{~min}, 4.5 \mathrm{~min}$ and $5 \mathrm{~min}$. Shown as follows:
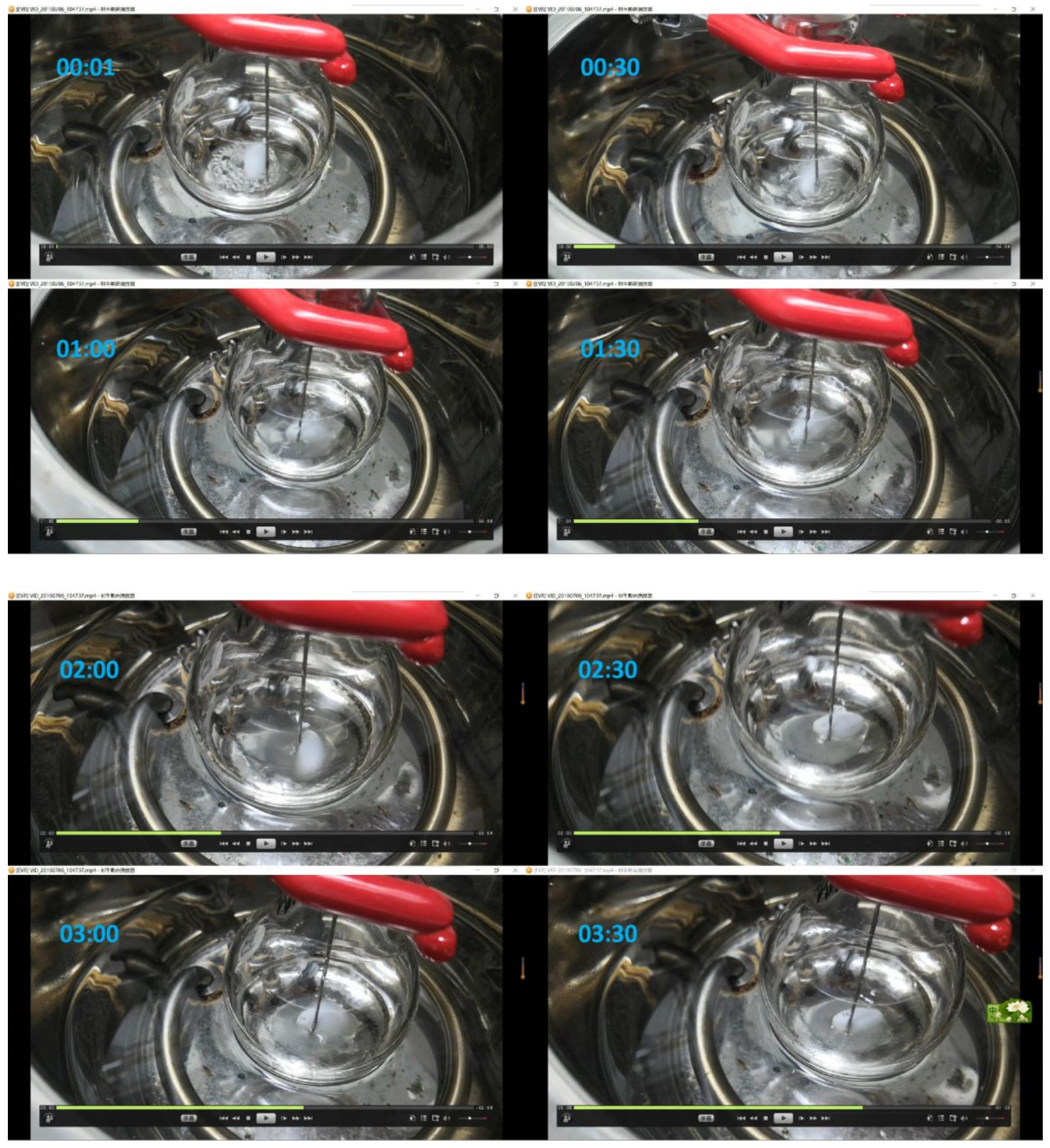

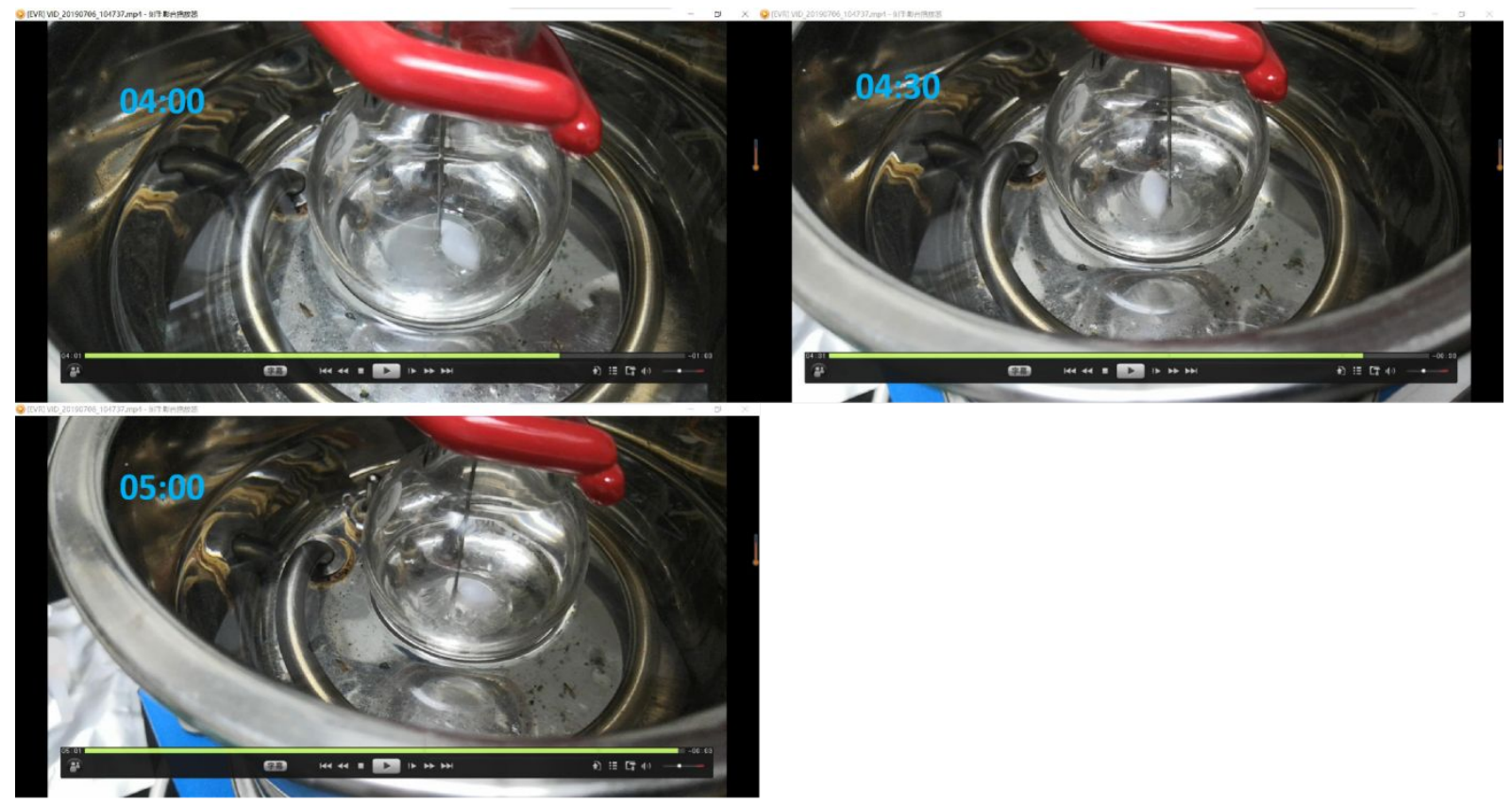

Figure S20. Video screenshots of the atmospheric copolymerization progress. 


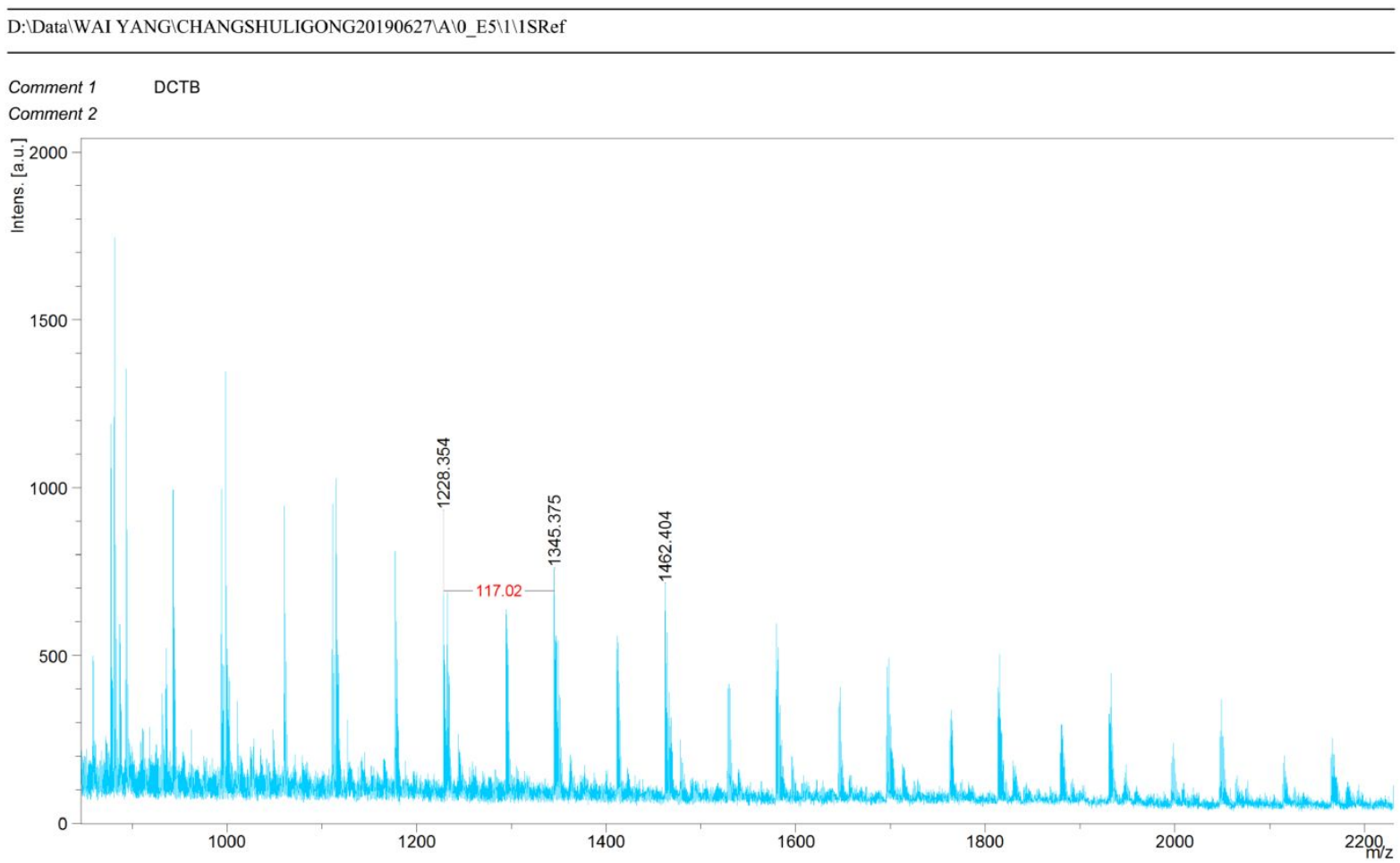

Figure S21. Original full-range MALDI-TOF-MS spectrum of entry 2 in Table 1.

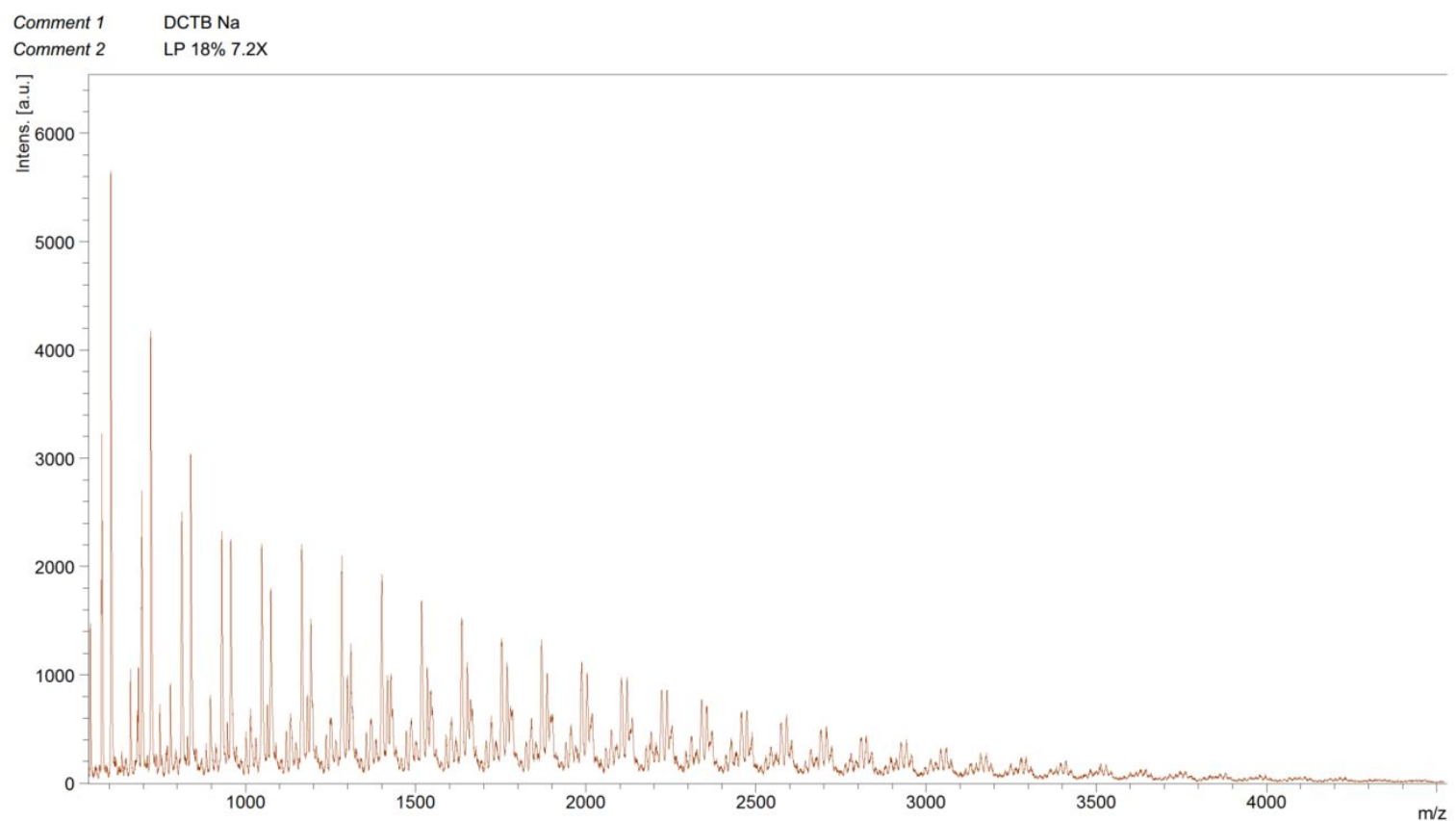

Figure S22. Original full-range MALDI-TOF-MS spectrum of entry 5 in Table 2. 


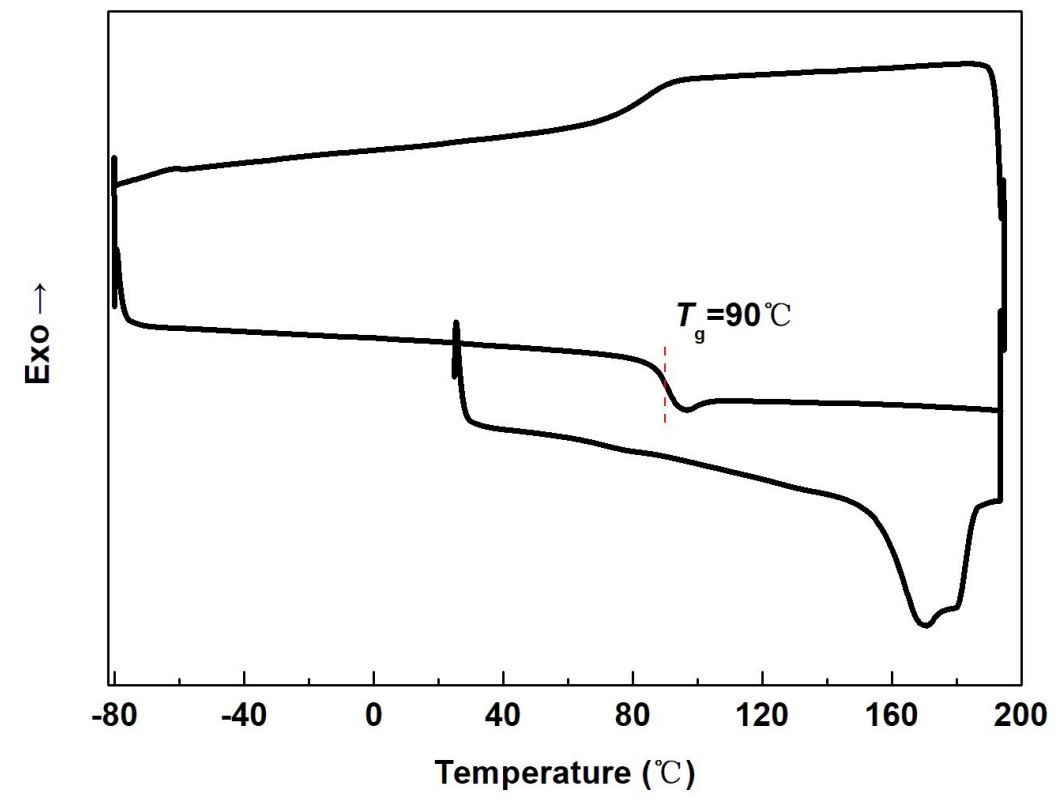

Figure S23. The DSC curve with the complete three run of the copolymer of entry 2 in Table 1.

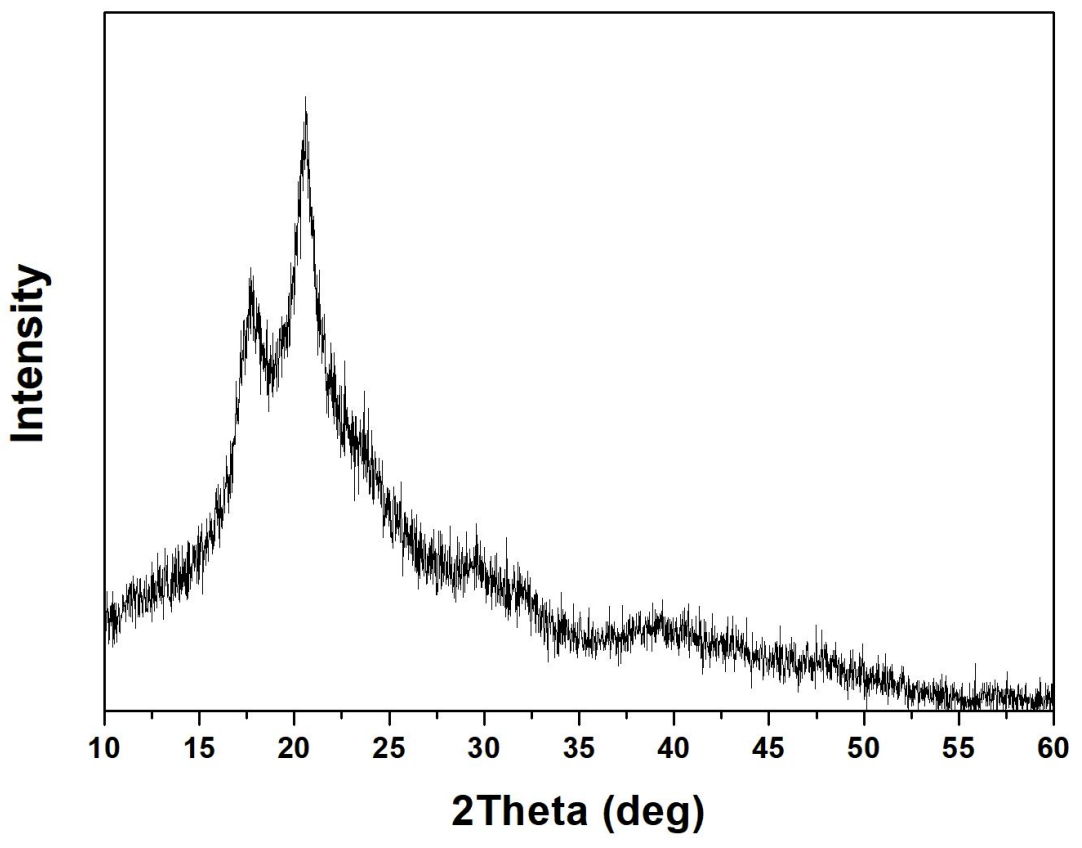

Figure S24. The powder X-ray diffraction (XRD) curve of the copolymer. 


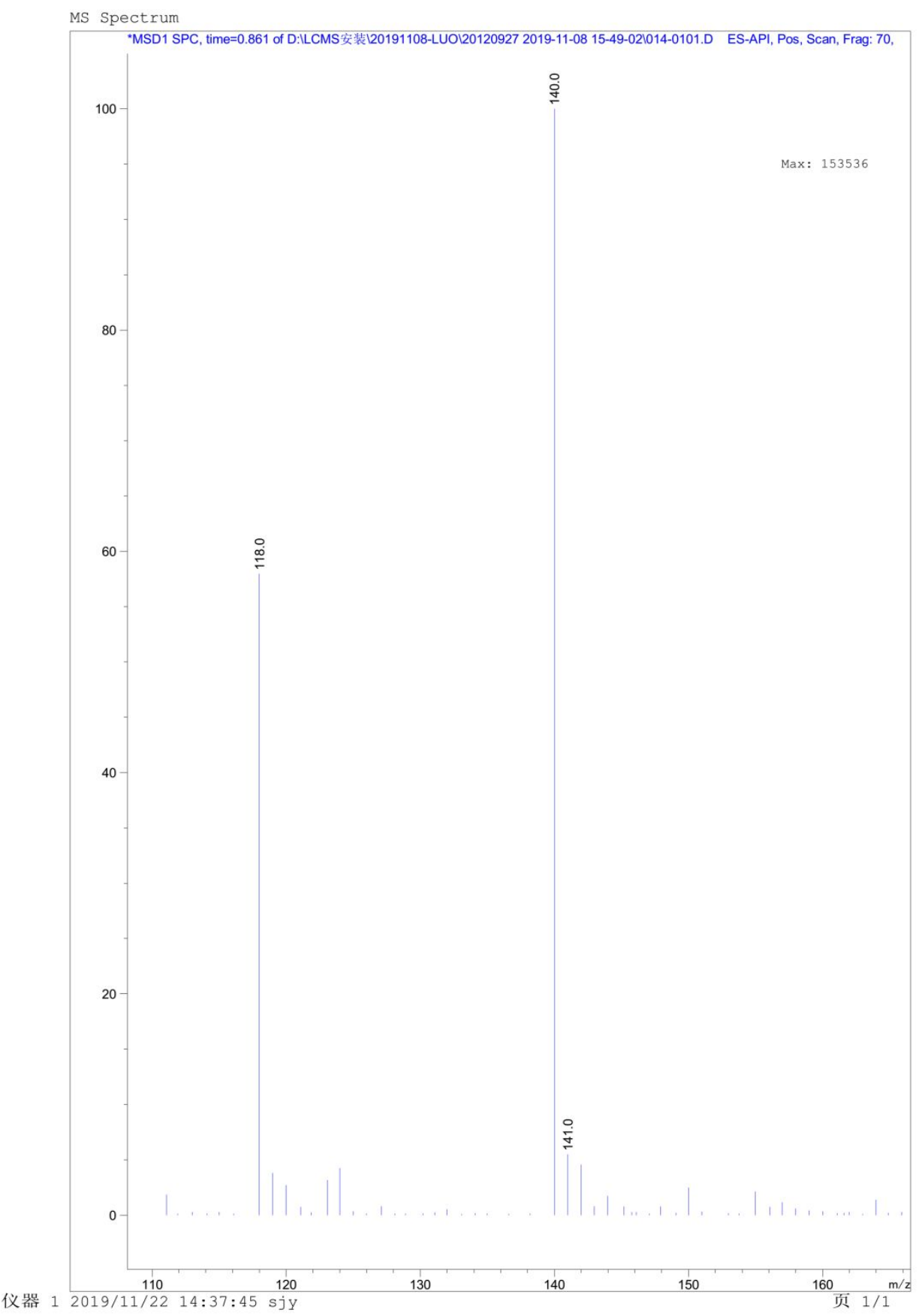

\begin{tabular}{|l|c|}
\hline Compound & 118.0 \\
\hline & 140.0 \\
\hline
\end{tabular}

Figure S25. The LC-MS spectrum of the cyclic product. 


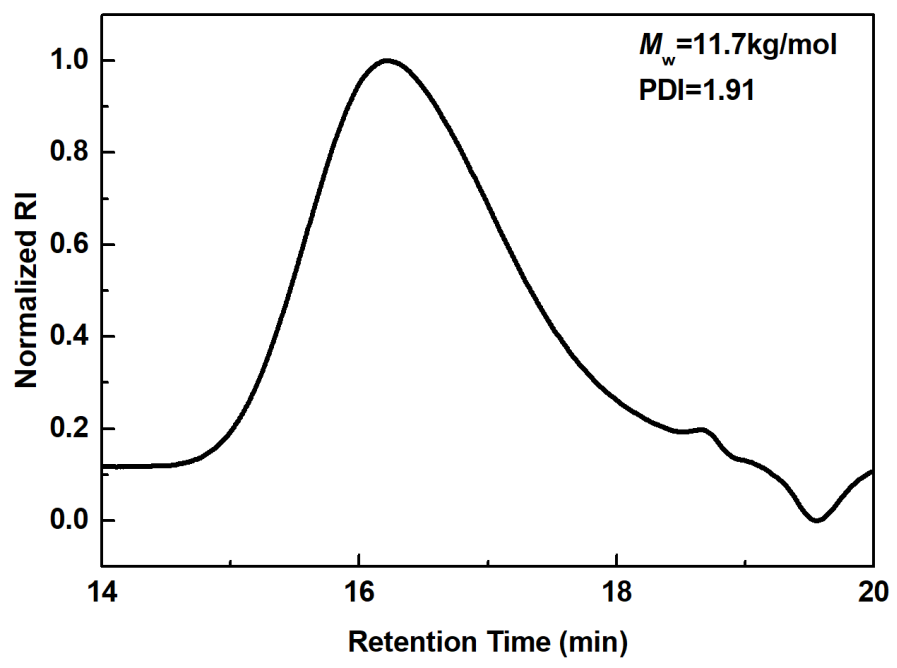

Figure S26. The GPC curve of entry 1 in Table 1.

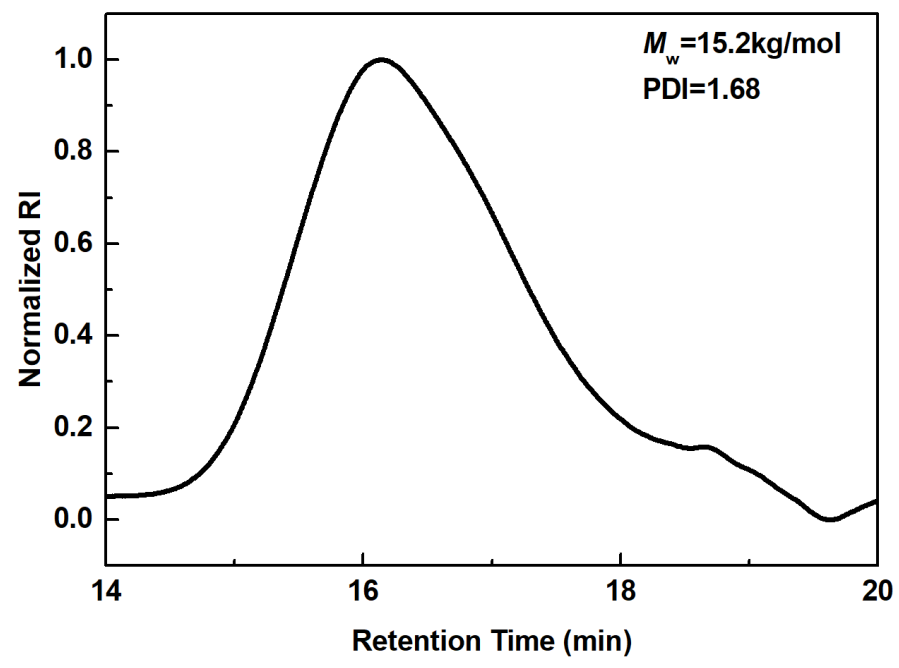

Figure S27. The GPC curve of entry 2 in Table 1. 


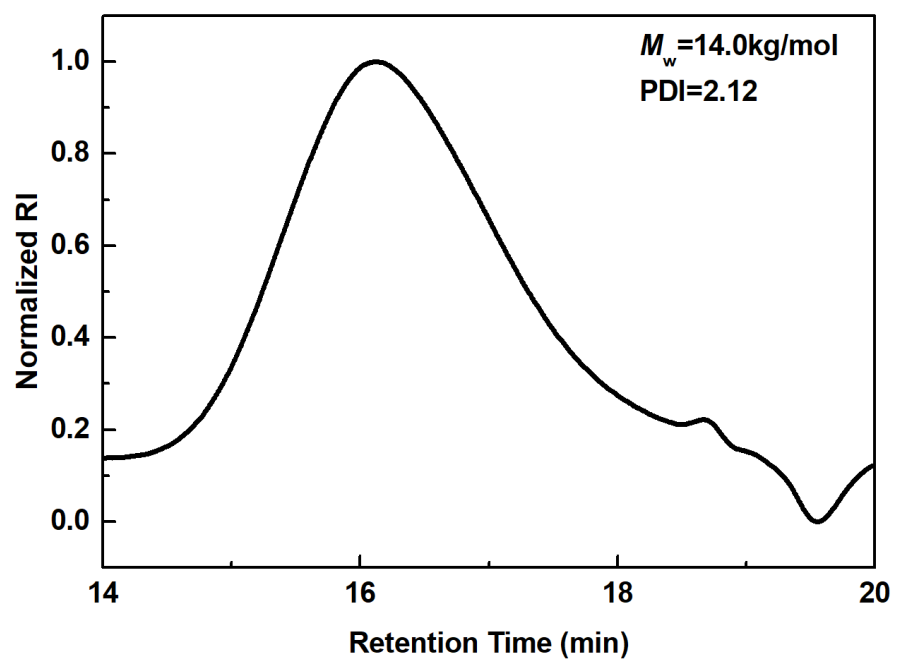

Figure S28. The GPC curve of entry 3 in Table 1.

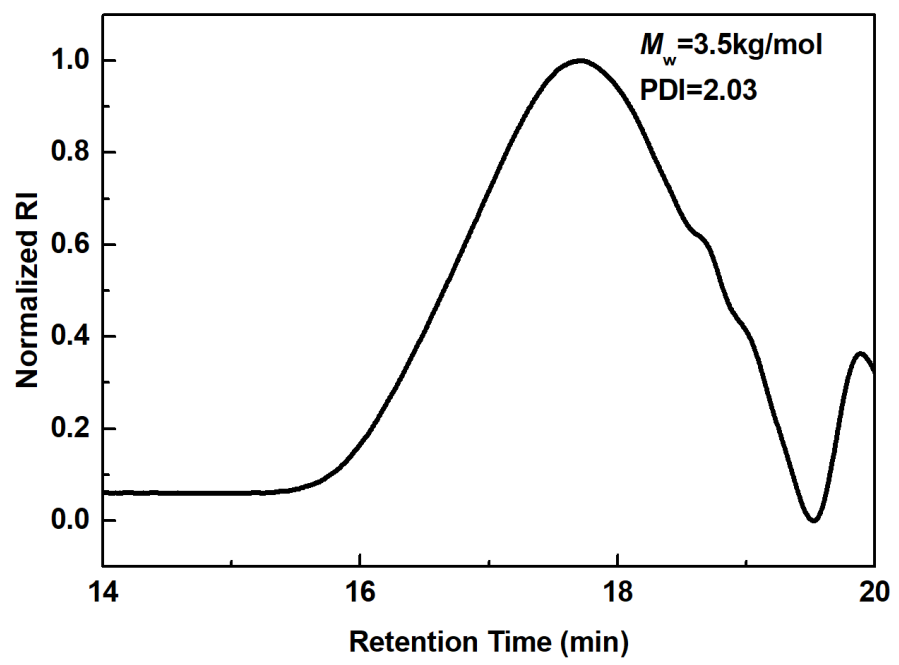

Figure S29. The GPC curve of entry 4 in Table 1. 


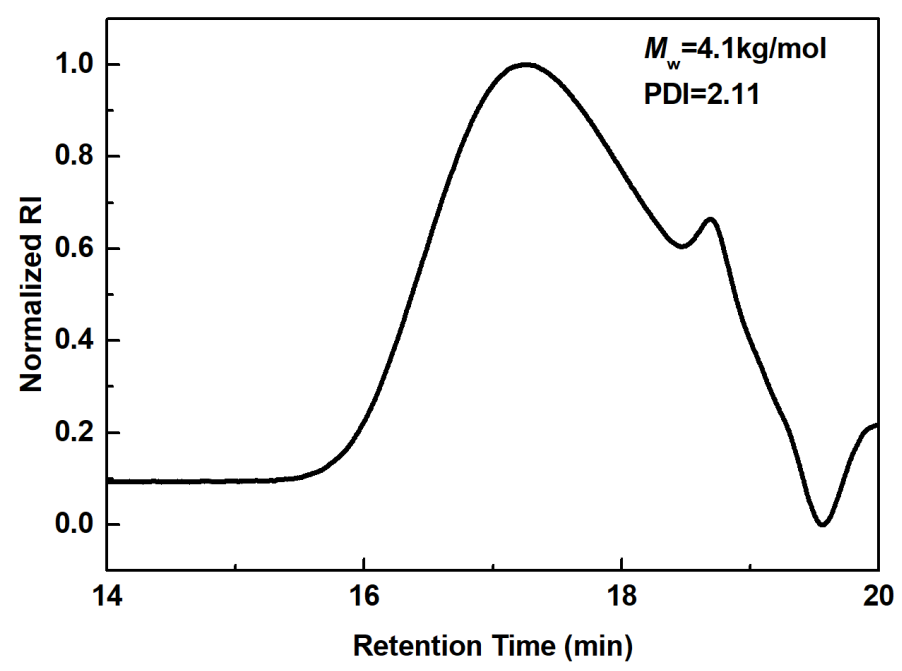

Figure S30. The GPC curve of entry 5 in Table 1.

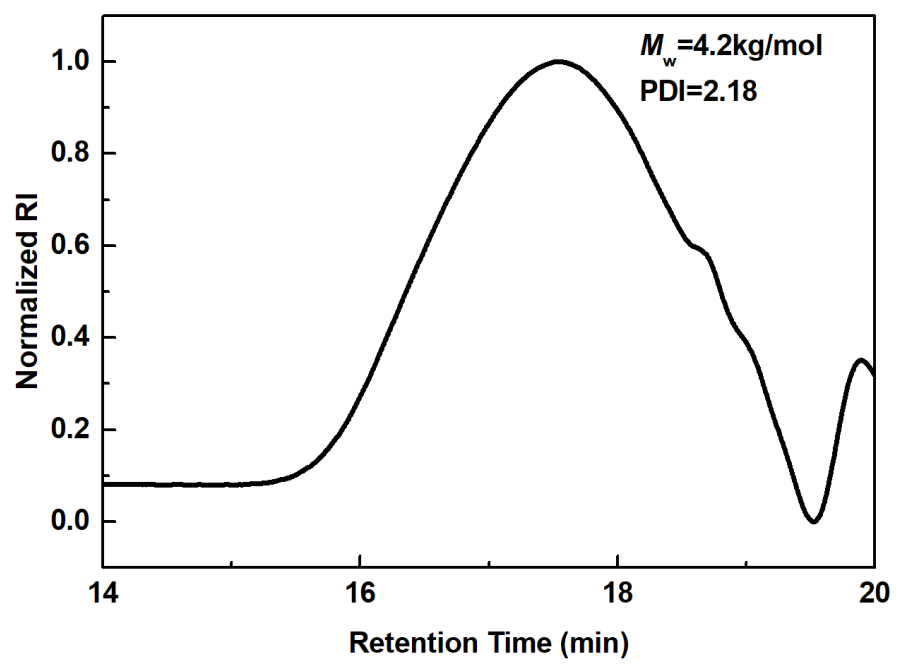

Figure S31. The GPC curve of entry 6 in Table 1. 


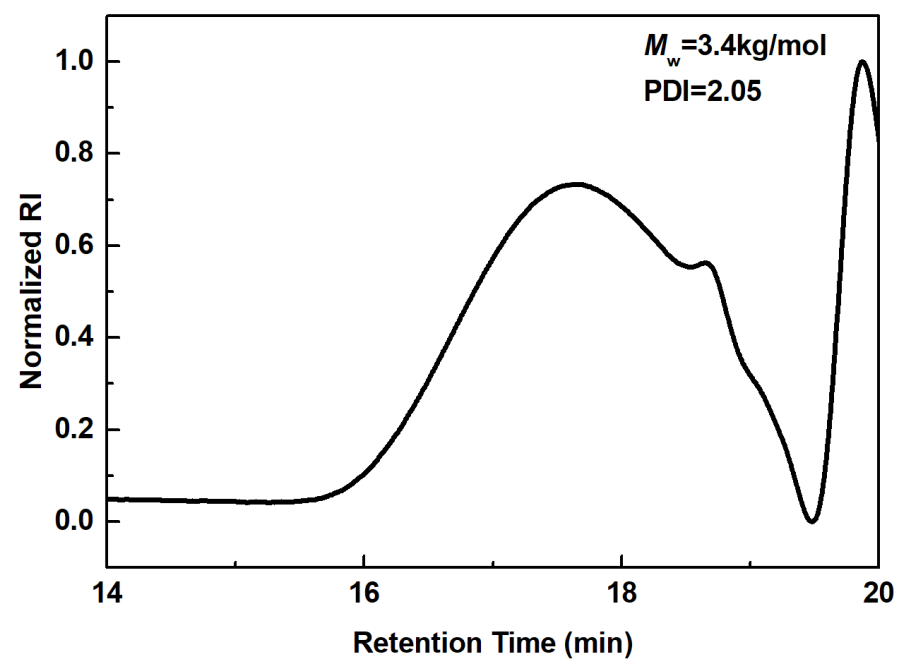

Figure S32. The GPC curve of entry 7 in Table 1.

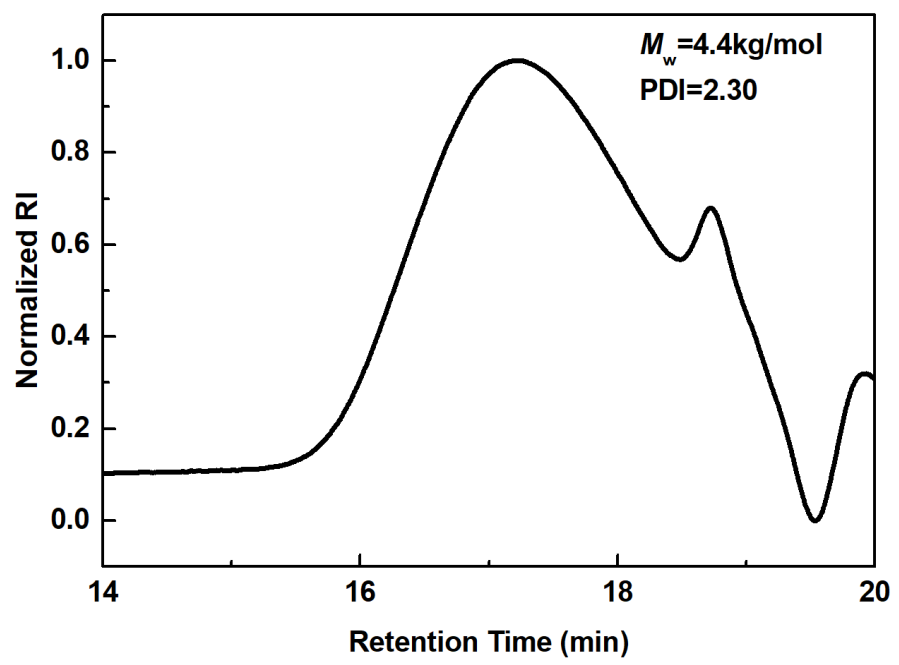

Figure S33. The GPC curve of entry 8 in Table 1. 


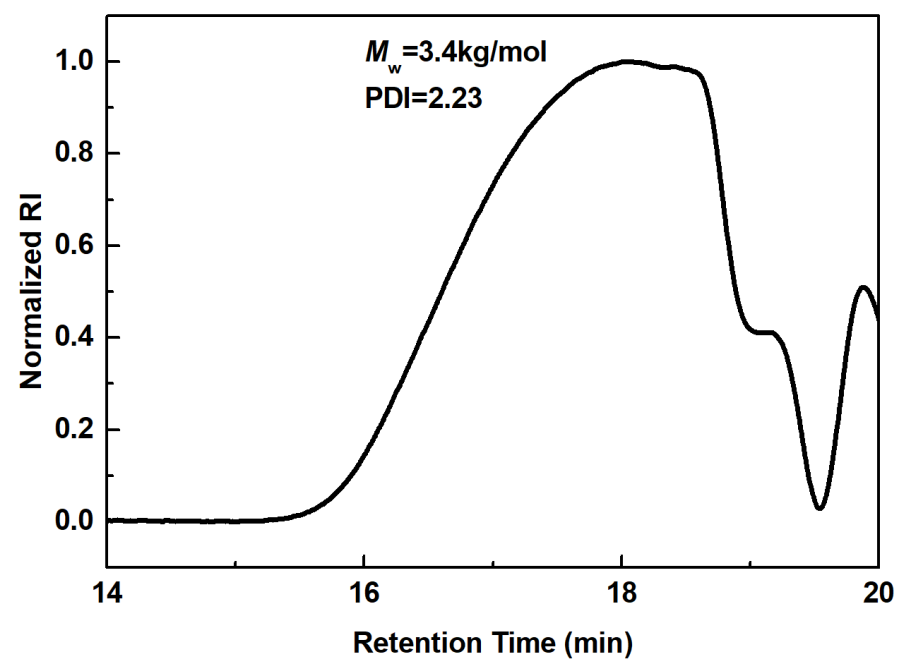

Figure S34. The GPC curve of entry 9 in Table 1.

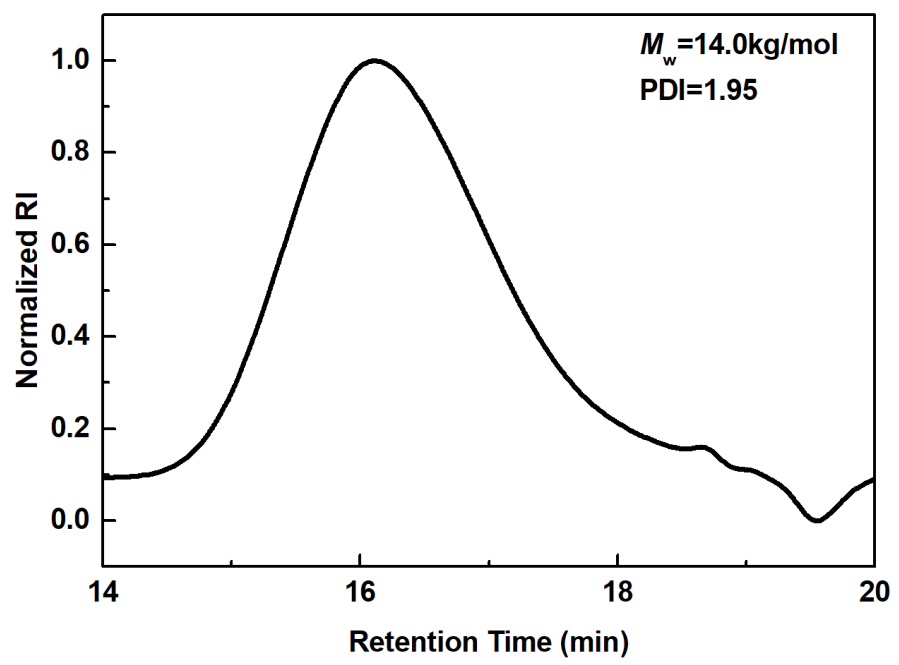

Figure S35. The GPC curve of entry 10 in Table 1. 


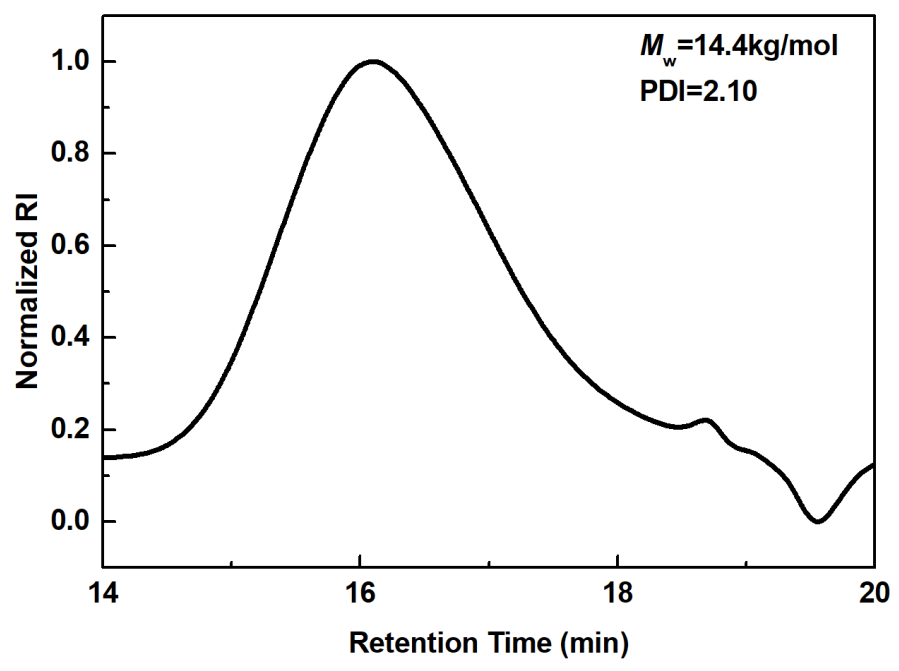

Figure S36. The GPC curve of entry 11 in Table 1.

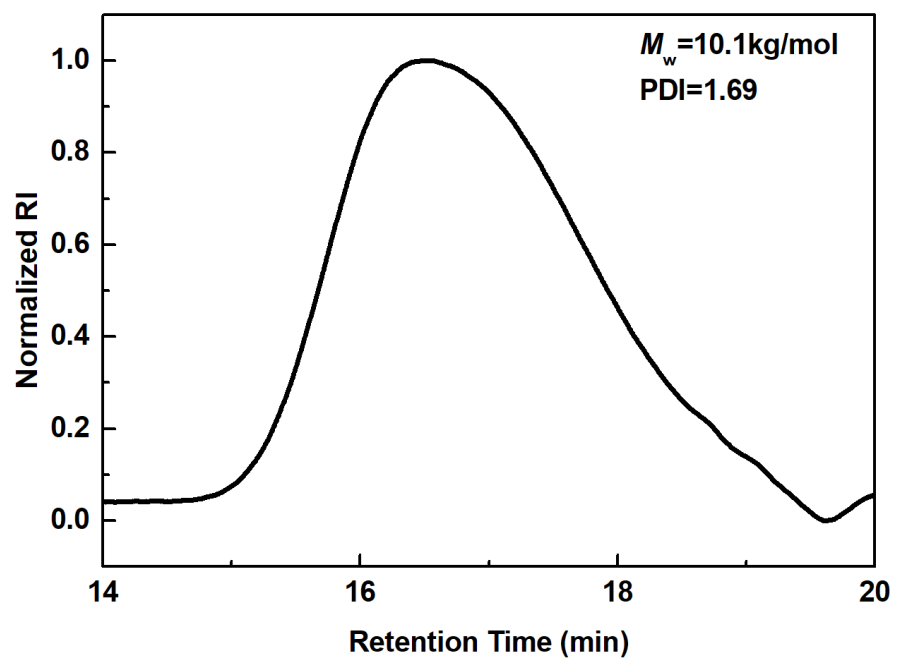

Figure S37. The GPC curve of entry 12 in Table 1. 


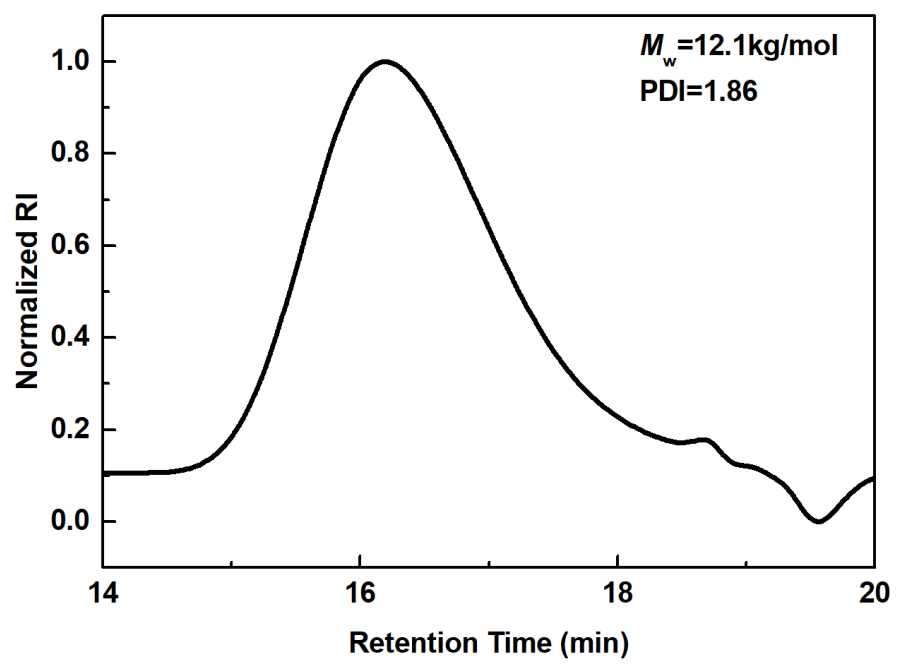

Figure S38. The GPC curve of entry 13 in Table 1.

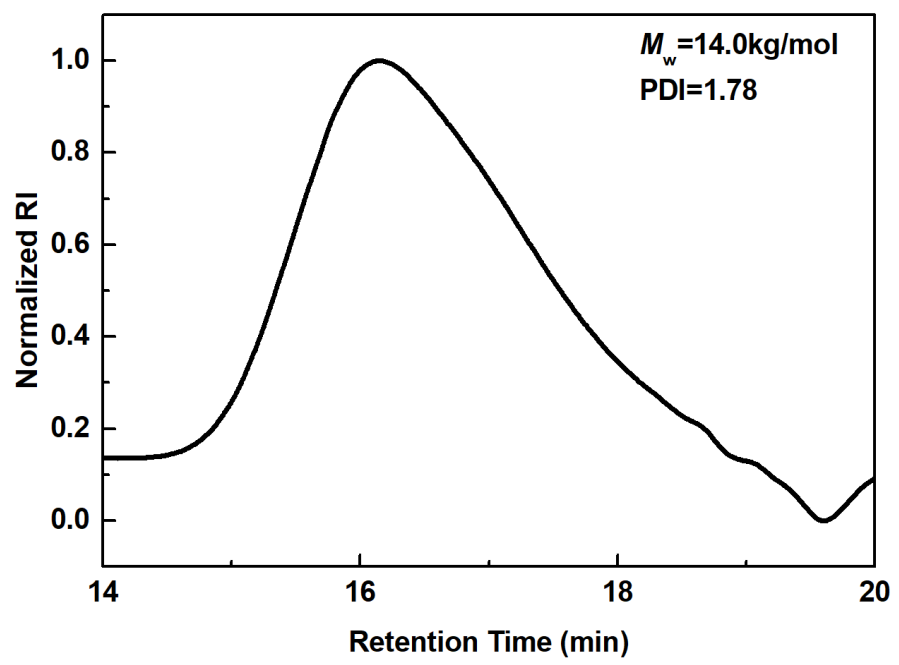

Figure S39. The GPC curve of entry 14 in Table 1. 


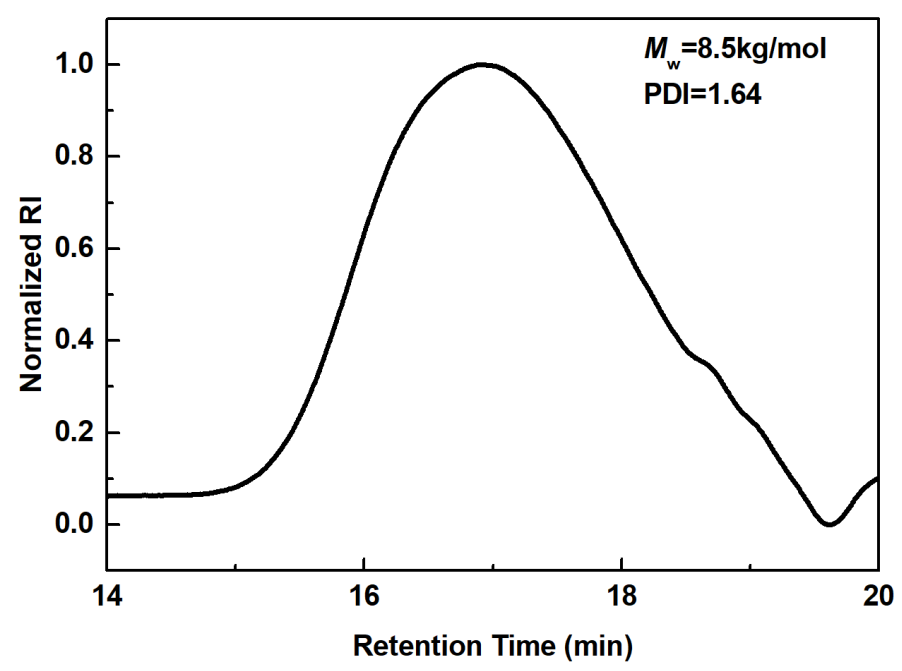

Figure S40. The GPC curve of entry 15 in Table 1.

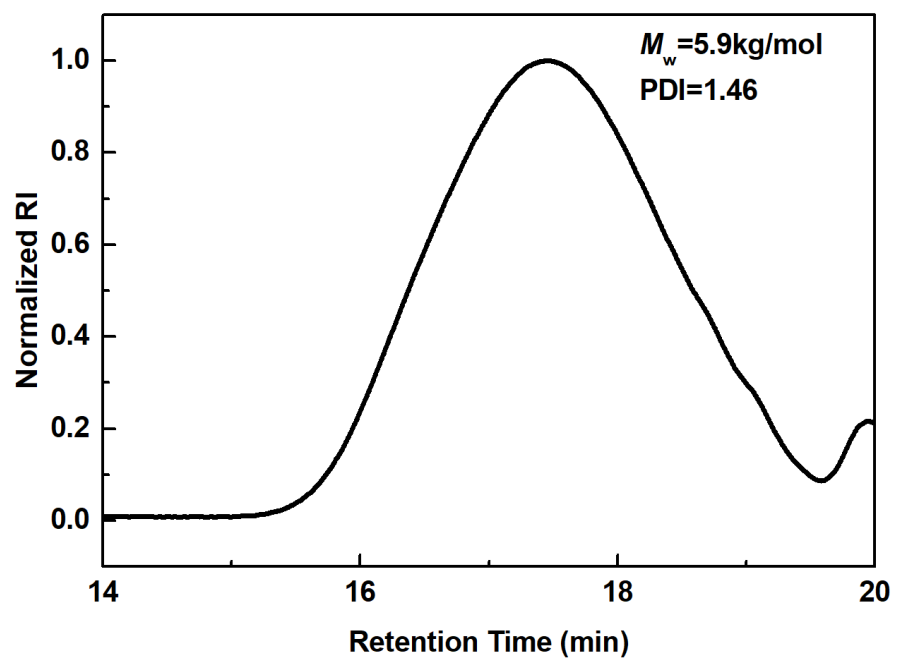

Figure S41. The GPC curve of entry 16 in Table 1. 


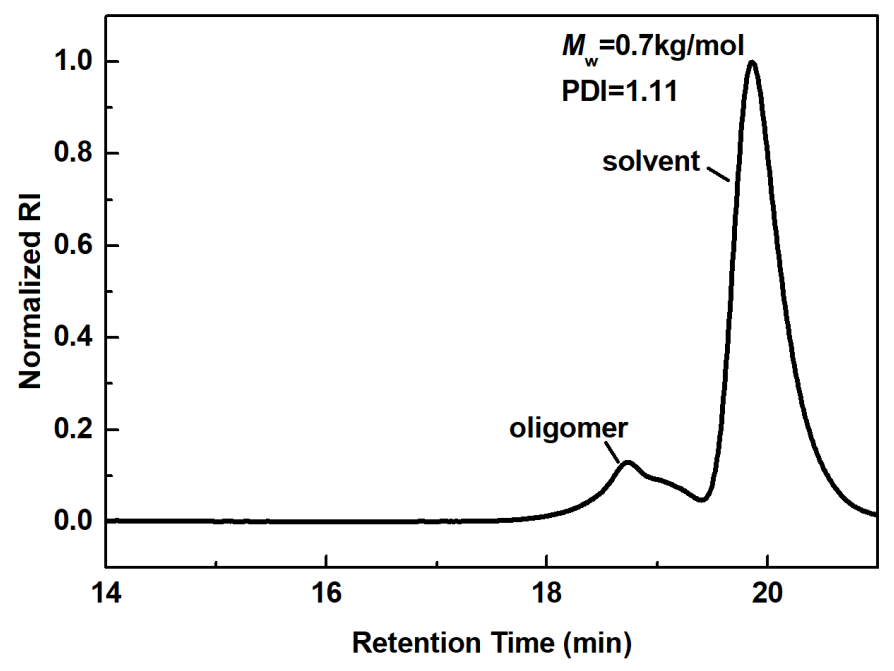

Figure S42. The GPC curve of entry 17 in Table 1.

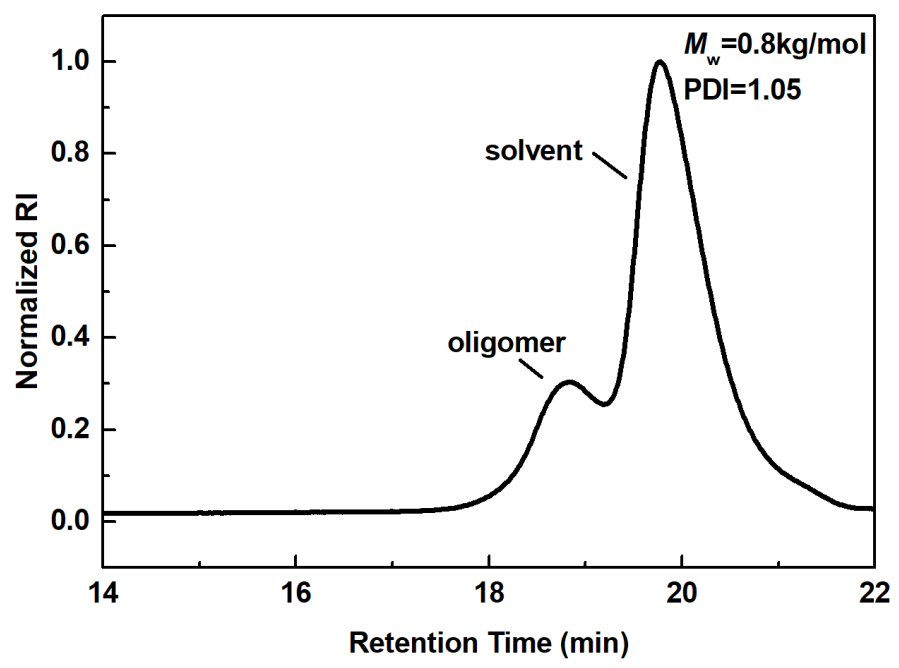

Figure S43. The GPC curve of entry 2 in Table 2. 


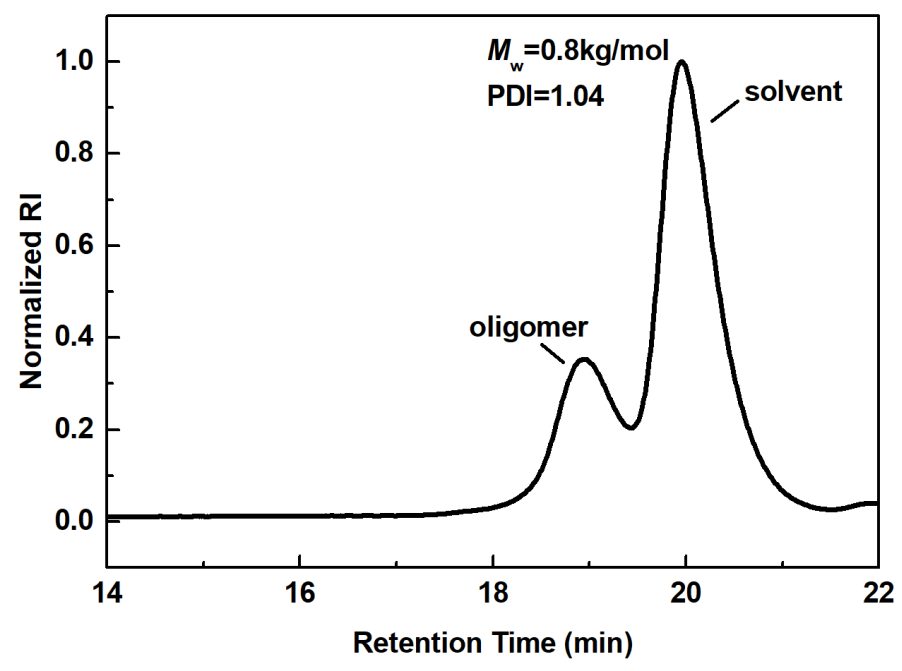

Figure S44. The GPC curve of entry 3 in Table 2.

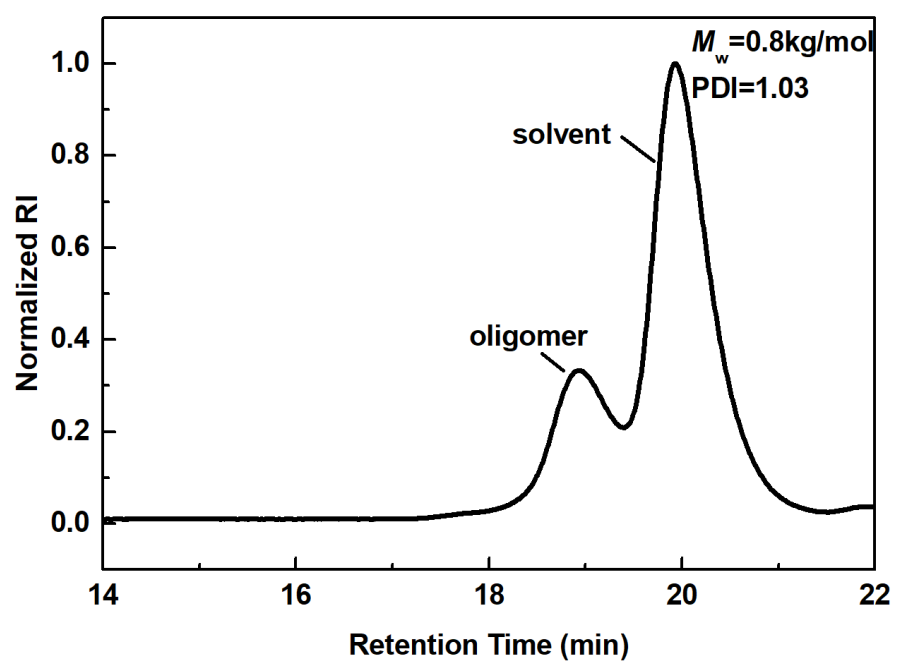

Figure S45. The GPC curve of entry 4 in Table 2. 


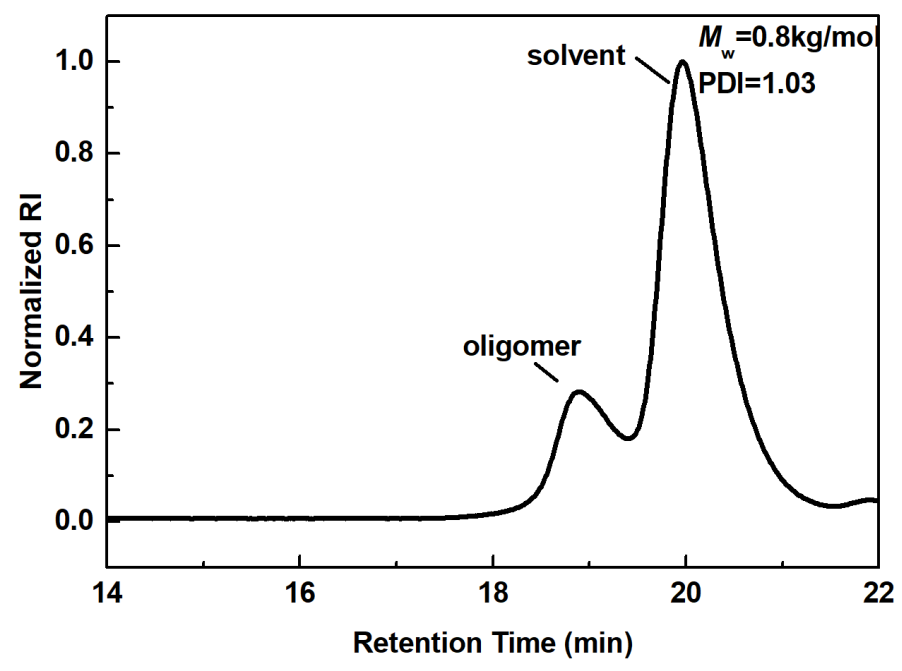

Figure S46. The GPC curve of entry 5 in Table 2.

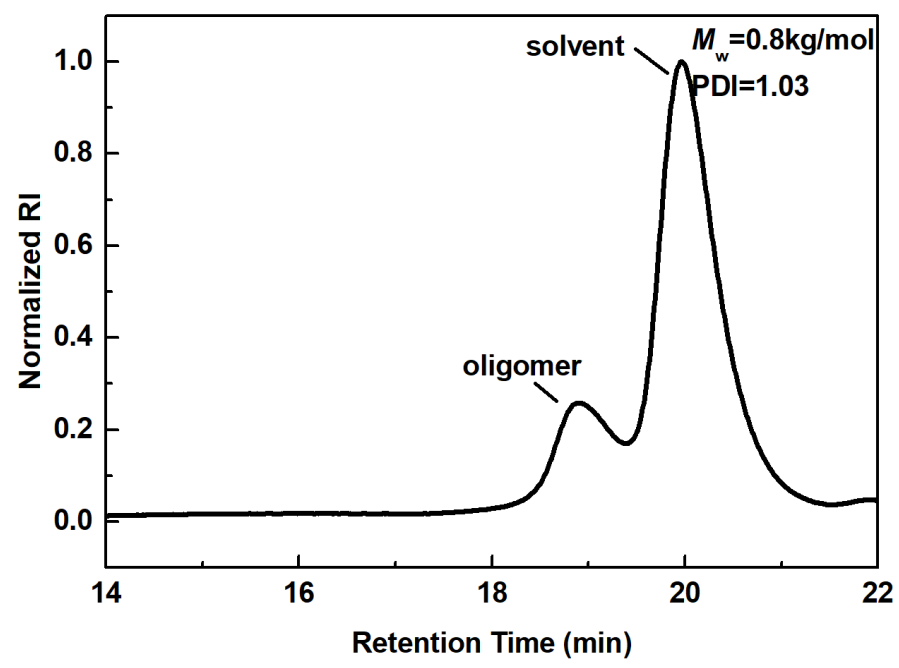

Figure S47. The GPC curve of entry 6 in Table 2. 


\section{XPS spectrum}

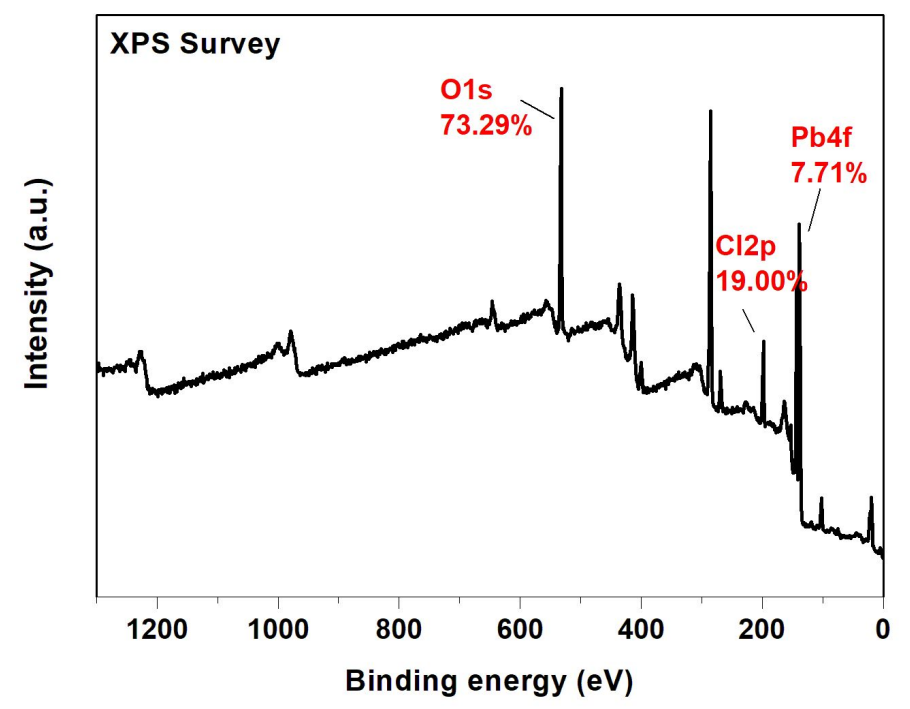

Figure S48. The XPS spectrum of the black solid in lead recovery.

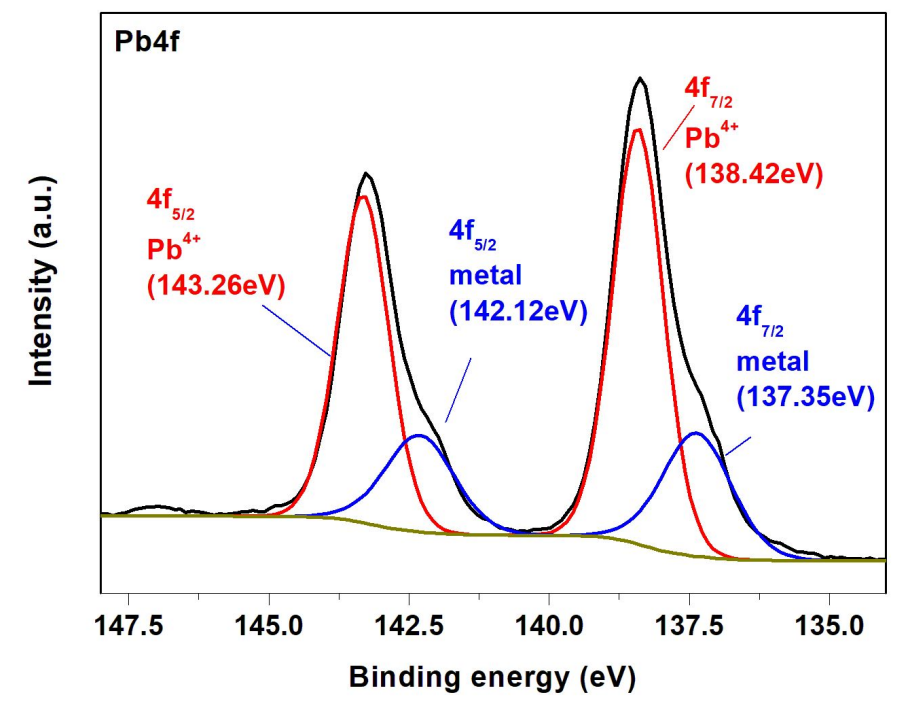

Figure S49. XPS spectra of the $\mathrm{Pb} 4 \mathrm{f}$ and depicted elemental quantification. 


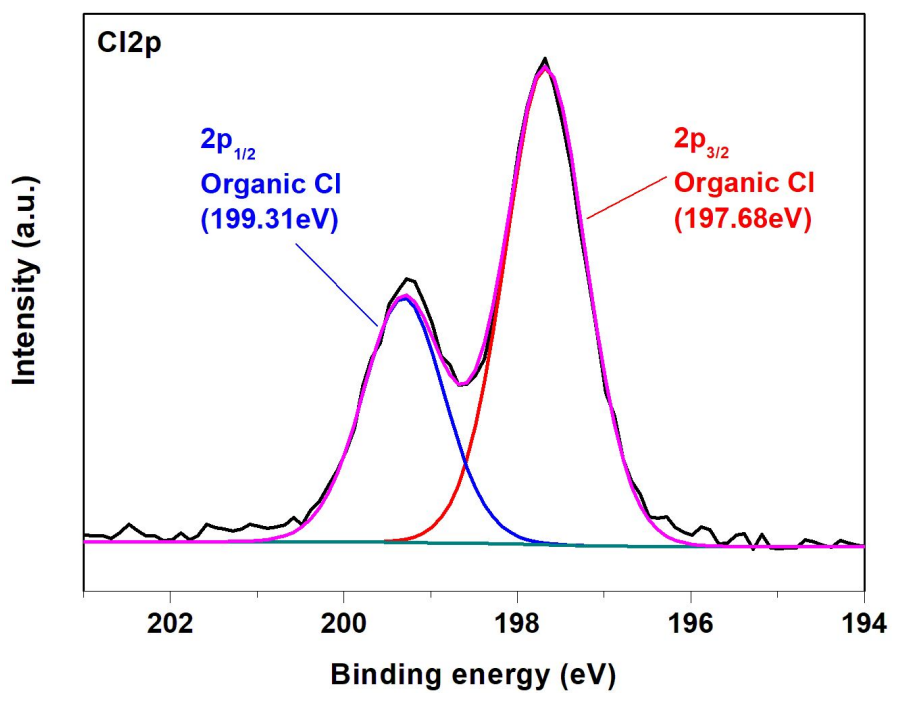

Figure S50. XPS spectra of the $\mathrm{Cl} 2 \mathrm{p}$ and depicted elemental quantification.

\section{References:}

1. Li, G.; Liu, Y.; Zhang, K.; Shi, J.; Wan, X.; Cao, S. Effect of salen-metal complexes on thermosensitive reversibility of stimuli-responsive water-soluble poly(urethane amine)s. J. Appl. Polym. Sci. 2013, 129, 3696-3703.

2. Osamu, I.; Yoshihito, K.; Takao, I. Synthesis of thermoresponsive polyurethane from 2methylaziridine and supercritical carbon dioxide. Angew. Chem. Int. Ed. 2004, 43, 717-719. 